\title{
Distinct diurnal variation in organic aerosol hygroscopicity and its relationship with oxygenated organic aerosol
}

\author{
Ye Kuang ${ }^{1, *}$, Yao He${ }^{2, *}$, Wanyun $\mathrm{Xu}^{5}$, Pusheng Zhao ${ }^{6}$, Yafang Cheng ${ }^{4}$, Gang Zhao ${ }^{3}$, Jiangchuan Tao ${ }^{1}, \mathrm{Nan}_{\mathrm{Ma}^{1}}$, \\ Hang Su ${ }^{4}$, Yanyan Zhang ${ }^{1}$, Jiayin Sun ${ }^{7}$, Peng Cheng ${ }^{7}$, Wenda Yang ${ }^{7}$, Shaobin Zhang ${ }^{1}$, Cheng $\mathrm{Wu}^{7}$, Yele Sun ${ }^{2}$, and \\ Chunsheng $\mathbf{Z h a o}^{3}$ \\ ${ }^{1}$ Institute for Environmental and Climate Research, Jinan University, Guangzhou 511443, China \\ ${ }^{2}$ State Key Laboratory of Atmospheric Boundary Layer Physics and Atmospheric Chemistry, \\ Institute of Atmospheric Physics, Chinese Academy of Sciences, Beijing 100029, China \\ ${ }^{3}$ Department of Atmospheric and Oceanic Sciences, School of Physics, Peking University, Beijing 100871, China \\ ${ }^{4}$ Max Planck Institute for Chemistry, 55128 Mainz, Germany \\ ${ }^{5}$ State Key Laboratory of Severe Weather \& Key Laboratory for Atmospheric Chemistry, \\ Institute of Atmospheric Composition, Chinese Academy of Meteorological Sciences, Beijing 100081, China \\ ${ }^{6}$ Institute of Urban Meteorology, China Meteorological Administration, Beijing 100089, China \\ ${ }^{7}$ Institute of Mass Spectrometer and Atmospheric Environment, Jinan University, Guangzhou 510632, China \\ *These authors contributed equally to this work.
}

Correspondence: Ye Kuang (kuangye@jnu.edu.cn) and Yele Sun (sunyele@mail.iap.ac.cn)

Received: 8 July 2019 - Discussion started: 30 September 2019

Revised: 6 December 2019 - Accepted: 19 December 2019 - Published: 23 January 2020

\begin{abstract}
The hygroscopicity of organic aerosol (OA) is important for investigation of its climatic and environmental impacts. However, the hygroscopicity parameter $\kappa_{\mathrm{OA}}$ remains poorly characterized, especially in the relatively polluted environment on the North China Plain (NCP). Here we conducted simultaneous wintertime measurements of bulk aerosol chemical compositions of $\mathrm{PM}_{2.5}$ and $\mathrm{PM}_{1}$ and bulk aerosol hygroscopicity of $\mathrm{PM}_{10}$ and $\mathrm{PM}_{1}$ on the NCP using a capture-vaporizer time-of-flight aerosol chemical speciation monitor (CV-ToF-ACSM) and a humidified nephelometer system which measures the aerosol light-scattering enhancement factor $f(\mathrm{RH})$. A method for calculating $\kappa_{\mathrm{OA}}$ based on $f(\mathrm{RH})$ and bulk aerosol chemical-composition measurements was developed. We found that $\kappa_{\mathrm{OA}}$ varied in a wide range with significant diurnal variations. The derived $\kappa_{\mathrm{OA}}$ ranged from almost 0.0 to 0.25 , with an average $( \pm 1 \sigma)$ of $0.08( \pm 0.06)$ for the entire study. The derived $\kappa_{\mathrm{OA}}$ was highly correlated with $f_{44}$ (fraction of $m / z 44$ in OA measured by CV-ToF-ACSM), an indicator of the oxidation degree of OA $(R=0.79)$, and the relationship can be parameterized as $\kappa_{\mathrm{OA}}=1.04 \times f_{44}-0.02\left(\kappa_{\mathrm{OA}}=0.3 \times \mathrm{O}: \mathrm{C}-0.02\right.$, based on the relationship between the $f_{44}$ and $\mathrm{O} / \mathrm{C}$ ratio
\end{abstract}

for CV-ToF-ACSM). On average, $\kappa_{\mathrm{OA}}$ reached the minimum (0.02) in the morning near 07:30 local time (LT) and then increased rapidly, reaching the peak value of 0.16 near 14:30 LT. The diurnal variations in $\kappa_{\mathrm{OA}}$ were highly and positively correlated with those of mass fractions of oxygenated OA $(R=0.95)$, indicating that photochemical processing played a dominant role in the increase in $\kappa_{\mathrm{OA}}$ in winter on the NCP. Results in this study demonstrate the potential wide applications of a humidified nephelometer system together with aerosol composition measurements for investigating the hygroscopicity of $\mathrm{OA}$ in various environments and highlight that the parameterization of $\kappa_{\mathrm{OA}}$ as a function of OA aging processes needs to be considered in chemical transport models for better evaluating the impacts of OA on cloud formation, atmospheric chemistry, and radiative forcing. 


\section{Introduction}

Aerosol hygroscopic growth plays significant roles in different atmospheric processes, including atmospheric radiation transfer, cloud formation, visibility degradation, atmospheric multiphase chemistry, and even air-pollution-related health effects, and is therefore crucial for studies on aerosol climatic and environmental impacts. Organic materials in ambient aerosol particles, usually referred to organic aerosol (OA), contribute substantially to ambient aerosol mass and often contribute to more than half of submicron aerosol particle mass under the dry state (Jimenez et al., 2009). The hygroscopicity parameter $\kappa$ (Petters and Kreidenweis, 2007) of organic aerosol $\left(\kappa_{\mathrm{OA}}\right)$ is a key parameter for investigating the roles of organic aerosol in radiative forcing, cloud formation, and atmospheric chemistry. Liu and Wang (2010) demonstrated that $50 \%$ increases in $\kappa$ of secondary organic aerosol $(0.14 \pm 0.07)$ can result in up to $40 \%$ increases in predicted cloud condensation nuclei (CCN) concentration. Rastak et al. (2017) reported that global average aerosol radiative forcing would decrease about $1 \mathrm{~W} \mathrm{~m}^{-2}$ should $\kappa_{\mathrm{OA}}$ increase from 0.05 to 0.15 , which is of the same order of the overall climate forcing of anthropogenic aerosol particles during the industrialization period. Li et al. (2019) reported that organic aerosol liquid water contributed $18 \%-32 \%$ to total particle liquid water content in Beijing. Despite its importance, $\kappa_{\mathrm{OA}}$ has not yet been characterized well due to the extremely complex chemical compositions of organic aerosol. Therefore, it is important to conduct more research on the spatiotemporal variation in $\kappa_{\mathrm{OA}}$ and its relationship with aerosol chemical compositions to reach a better characterization and come up with more appropriate parameterization schemes in chemical, meteorological, and climate models.

The large variety in OA chemical constituents makes it difficult to directly link $\kappa_{\mathrm{OA}}$ to specific organic aerosol compositions. The OA chemical composition is tightly connected to its volatile organic precursors, which are also rich in variety and come from different natural and anthropogenic sources. OA with different oxidation levels also behaves differently with respect to hygroscopic growth. Thus, studies on $\kappa_{\mathrm{OA}}$ at different locations and seasons have reported distinct characteristics. Many studies have investigated the influence of the OA oxidation level (represented by the $\mathrm{O}: \mathrm{C}$ ratio or fraction of $m / z, 44$ in OA, $f_{44}$, which is determined from aerosol mass spectrometer measurements) on its hygroscopicity (Chang et al., 2010; Lambe et al., 2011; Duplissy et al., 2011; Mei et al., 2013b; Wu et al., 2013; Hong et al., 2015; Chen et al., 2017; Massoli et al., 2010) and found that the average $\kappa_{\mathrm{OA}}$ generally increases as a function of the organic aerosol oxidation level. However, the statistical empirical relationship between $\kappa_{\mathrm{OA}}$ and $\mathrm{O}: \mathrm{C}$ ratio or $f_{44}$ differs much among different studies. Several studies have also analyzed the diurnal variation characteristics of $\kappa_{\mathrm{OA}}$ at different locations and seasons (Cerully et al., 2015; Bougiatioti et al., 2016; Deng et al., 2018, 2019; Thalman et al., 2017), with some exhibiting distinct diurnal variations (Deng et al., 2018, 2019; Bougiatioti et al., 2016) and others not exhibiting variations (Cerully et al., 2015). Despite this, the studies on $\kappa_{\mathrm{OA}}$ in the relatively polluted North China Plain (NCP) region are very limited (Wu et al., 2016). The diurnal characteristics of $\kappa_{\mathrm{OA}}$ on the NCP have not been reported so far. Therefore, more investigation into the diurnal variation in $\kappa_{\mathrm{OA}}$ and its relationship with the OA oxidation level is required to better understand its characteristics in the NCP.

The humidity tandem differential mobility analyzer (HTDMA), or CCN counter, has been widely used for aerosol hygroscopicity measurements. Both the HTDMA and sizeresolved $\mathrm{CCN}$ measurements can only be used to derive a $\kappa$ within a certain size range (HTDMA: usually with a diameter below $300 \mathrm{~nm}$ and with a reported highest diameter of $360 \mathrm{~nm}$ - Deng et al., 2019; CCN: with a diameter of up to $\sim 200 \mathrm{~nm}-$ Zhang et al., 2014; Rose et al., 2010). The aerosol particles contributing most to aerosol optical properties (Bergin et al., 2001; Quinn et al., 2002; Cheng et al., 2008; Ma et al., 2011; Kuang et al., 2018) and aerosol liquid water content (Bian et al., 2014) in continental regions are usually in the diameter range of $200 \mathrm{~nm}$ to $1 \mu \mathrm{m}$, which the HTDMA and CCN hygroscopicity measurements cannot represent. Results from several studies have reported that $\kappa_{\mathrm{OA}}$ usually differentiates among particle sizes (Frosch et al., 2011; Kawana et al., 2016; Deng et al., 2019). For example, Deng et al. (2019) found that $\kappa_{\mathrm{OA}}$ increases with the increases in the particle dry diameter. These results further highlight a need for characterization of $\kappa_{\mathrm{OA}}$ of larger particles.

The humidified nephelometer system which measures aerosol light-scattering enhancement factors is also widely used in aerosol hygroscopicity research (Titos et al., 2016). The hygroscopicity parameter $\kappa$ retrieved from the measured light-scattering enhancement factor is usually referred to as $\kappa_{f(\mathrm{RH})}$ (Chen et al., 2014; Kuang et al., 2017), which represents the overall hygroscopicity of aerosol particles, with their diameters ranging from 200 to $800 \mathrm{~nm}$ for continental aerosol (see discussions in Sect. 3.3 for physical understanding of $\kappa_{f(\mathrm{RH})}$ ). Using the retrieved $\kappa_{f(\mathrm{RH})}$ together with bulk aerosol chemical compositions of $\mathrm{PM}_{1}$ (particulate matter with an aerodynamic diameter of less than $1 \mu \mathrm{m}$, corresponding to a mobility diameter of approximately $760 \mathrm{~nm}$ assuming spherical particles and a particle density of $1.7 \mathrm{~g} \mathrm{~cm}^{-3}$ ), $\kappa_{\mathrm{OA}}$ can be derived, representing the hygroscopicity of organic aerosol particles in the diameter range of 200 to about $800 \mathrm{~nm}$. In this study, the light-scattering enhancement factors of both $\mathrm{PM}_{10}$ (particulate matter with an aerodynamic diameter less than $10 \mu \mathrm{m})$ and $\mathrm{PM}_{1}$ particles were measured at a rural site on the NCP in winter 2018, together with aerosol chemical compositions by a capture-vaporizer time-of-flight aerosol chemical speciation monitor (CV-ToF-ACSM). By integrating these two different measurements, $\kappa_{\mathrm{OA}}$ is derived, and the relationship between the $\kappa_{\mathrm{OA}}$ and OA oxidation degree, as well as the diurnal variation in $\kappa_{\mathrm{OA}}$, is elucidated. 


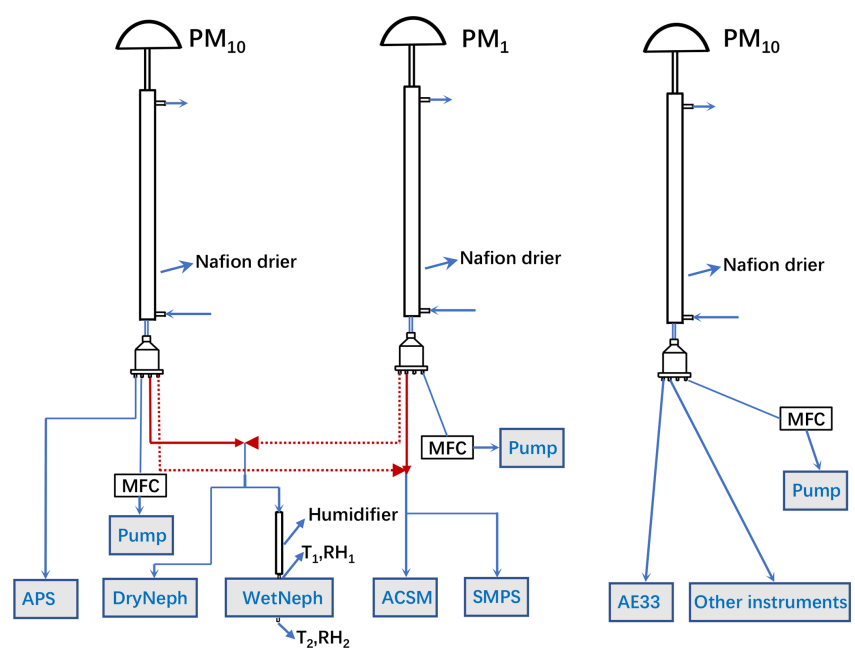

Figure 1. Schematic diagram of the inlet systems for aerosol sampling instruments.

\section{Site and instruments}

From 11 November to 24 December 2018, continuous measurements of physical, optical, and chemical properties of ambient aerosol particles as well as meteorological parameters such as temperature, wind speed and direction, and relative humidity were made at the Gucheng site in Dingxing County, Hebei province, China. The sampling site, an Ecological and Agricultural Meteorological Test Station $\left(39^{\circ} 09^{\prime} \mathrm{N}, 115^{\circ} 44^{\prime} \mathrm{E}\right)$ of the Chinese Academy of Meteorological Sciences, is located between Beijing $(\sim 100 \mathrm{~km})$ and Baoding $(\sim 40 \mathrm{~km})$, two large cities on the North China Plain, and is surrounded by farmland and small residential towns.

\subsection{Inlet system and instruments}

During this field campaign, all instruments were housed in an air-conditioned container, with the temperature held almost constant near $24^{\circ}$. The schematic diagram of the inlet systems for the aerosol sampling instruments is displayed in Fig. 1. Three inlet impactors are used for aerosol sampling, two $\mathrm{PM}_{10}$ inlets and one $\mathrm{PM}_{1}$ inlet, respectively sampling ambient aerosol particles with an aerodynamic diameter less than 10 and $1 \mu \mathrm{m}$. Nafion driers with lengths of $1.2 \mathrm{~m}$ were placed downstream of each PM impactor inlet, which can drop the RH of sampled air below $15 \%$; thus, sampled aerosol particles can be treated as being in the dry state. Additionally, downstream of every PM impactor inlet, an MFC (mass flow controller) and a pump were added for automatic flow compensation to ensure that each impactor reaches its required flow rate of $16.7 \mathrm{~L} \mathrm{~min}^{-1}$ and guarantee the right cut diameters.

Aerosol sampling instruments can be categorized into four groups according to their inlet routes. The first group (group 1) downstream of the first $\mathrm{PM}_{10}$ inlet is comprised of only one instrument, the Aerodynamic Particle Sizer (APS, TSI Inc., Model 3321), measuring the size distribution of ambient aerosol particles with an aerodynamic diameter ranging from $700 \mathrm{~nm}$ to $20 \mu \mathrm{m}$ at a temporal resolution of $20 \mathrm{~s}$. The second group (group 2) includes a humidified nephelometer system (consisting of two nephelometers and a humidifier) that measures aerosol optical properties (scattering and backscattering coefficients at three wavelengths: 450, 525, and $635 \mathrm{~nm}$ ) of ambient aerosol particles in the dry state (DryNeph) and under $85 \%$ RH condition (WetNeph). The third group (group 3) includes two instruments, an ACSM and a scanning mobility particle sizer (SMPS; TSI model 3080). The CV-ToF-ACSM measures non-refractory particulate matter (NR-PM) species including organics, $\mathrm{SO}_{4}^{2-}$, $\mathrm{NO}_{3}^{-}, \mathrm{NH}_{4}^{+}$, and $\mathrm{Cl}^{-}$, with an air flow of $0.1 \mathrm{~L} \mathrm{~min}^{-1}$ and a time resolution of $2 \mathrm{~min}$. Since the CV-ToF-ACSM instrument comes with a $\mathrm{PM}_{2.5}$ impactor, when the impactor of upstream is $\mathrm{PM}_{10}$, chemical compositions of $\mathrm{PM}_{2.5}$ rather than of $\mathrm{PM}_{10}$ were measured.

The SMPS measures particle mobility diameter size distributions with a diameter range of 12 to $760 \mathrm{~nm}$. The inlets of group 2 and group 3 switch every $15 \mathrm{~min}$, as denoted by the dashed and solid red lines in Fig. 1, enabling the instruments of these two groups to alternately measure the chemical and optical properties of $\mathrm{PM}_{10}$ and $\mathrm{PM}_{1}$. The fourth group (group 4) includes an AE33 aethalometer (Drinovec et al., 2015) and other aerosol instruments. Due to technical issues with the humidifier, the humified nephelometer system started to operate continuously on the 30 November.

\subsection{The humidified nephelometer system}

The humidified nephelometer system we built was set up to measure dry-state aerosol optical properties at a fixed RH of $85 \%$. The RH of the air sample is increased by a humidifier that consists of two layers. The inner layer is a Gore-Tex tube layer passing through sampled air, while the outer layer is a stainless-steel tube with circulating liquid water. The water vapor penetrates through the Gore-Tex tube and humidifies the sample air, while liquid water is kept from the inner layer by the Gore-Tex material. Upon the switch of inlets between group 2 and group 3, delays in valve switching caused instantaneous low pressure in the sample air, which broke the humidifier with the Gore-Tex tube after $4 \mathrm{~d}$ of continuous operation (3 December) and flooded the WetNeph. The WetNeph was fixed and recalibrated, and a commercial Nafion drier (60 cm long; Perma Pure company) replaced the Gore-Tex tube, which works the same way but is more resistant to low pressure. The temperature of the circulating water layer is controlled by a water bath and specified by an algorithm that adjusts the water temperature to maintain a relatively constant RH in the sensing volume of the WetNeph. To monitor the RH in the sensing volume of the WetNeph, two temperature and RH sensors (Vaisala HMP110, with accuracies of 
$\pm 0.2^{\circ}$ and $\pm 1.7 \%$ for RH between $0 \%$ to $90 \%$, respectively, and $\pm 2.5 \%$ for RH between $90 \%$ to $100 \%$ ) were placed at the inlet and outlet of the WetNeph. Defining measured RHs and temperatures at the inlet and outlet of the WetNeph as $\mathrm{RH}_{1} / T_{1}$ and $\mathrm{RH}_{2} / T_{2}$, the according dew point temperatures $T_{\mathrm{d} 1}$ and $T_{\mathrm{d} 2}$ can be calculated, and the average value $\overline{T_{\mathrm{d}}}$ was treated as the dew point of the sample air in the sensing volume of WetNeph. The sample RH is calculated using $\overline{T_{\mathrm{d}}}$ and the sample temperature measured by a sensor inside the sample cavity of the nephelometer.

\subsection{ACSM measurements and data analysis}

The mass concentration and chemical composition of NRPM species were measured with the Aerodyne ToF-ACSM, which is equipped with a $\mathrm{PM}_{2.5}$ aerodynamic lens (Williams et al., 2010) and a capture vaporizer (CV; Xu et al., 2017; $\mathrm{Hu}$ et al., 2017) to extend the measured particle size to $2.5 \mu \mathrm{m}$. Detailed instrument descriptions were given in Fröhlich et al. (2013) and Xu et al. (2017). The CV-ToF-ACSM data were analyzed with the standard data analysis software (Tofware v2.5.13; https://sites.google.com/site/ariacsm/, last access: 21 January 2020) within Igor Pro (v6.37; WaveMetrics, Inc., Oregon, USA). The CV was designed with an enclosed cavity to increase particle collection efficiency (CE) at the detector (Xu et al., 2017). Field measurements indicate that the $\mathrm{CE}$ of $\mathrm{CV}$ was fairly robust and was roughly equivalent to 1 . Therefore, a CE of 1 was applied to all measured species in this study (Hu et al., 2017, 2018b). Relative ionization efficiencies (RIEs) of 3.06 and 1.09 were used for ammonium and sulfate quantification, respectively, and the default values of 1.1 and 1.4 were used for nitrate and organic aerosol (OA), respectively. Compared with the AMS with a standard vaporizer, the CV-ToF-ACSM reports higher fragments at smaller $m / z$ values due to additional thermal decomposition associated with increased residence time and hot surface collisions (Hu et al., 2018a). As a result, $f_{44}$ values from CV-ToF-ACSM measurements are often much higher than those previously reported from AMS, yet they are well correlated (Hu et al., 2018a).

The organic mass spectra from $\mathrm{m} / \mathrm{z} 12$ to 214 were analyzed by positive matrix factorization (PMF; Paatero and Tapper, 1994) with an Igor Pro-based PMF evaluation tool (v3.04; Ulbrich et al., 2009). The ion fragments $m / z$ of 38, 49,63 , and 66 were removed from both $\mathrm{PM}_{1}$ and $\mathrm{PM}_{2.5} \mathrm{PMF}$ inputs, considering their small contributions to the total organic signals yet high signal-to-noise ratios. The PMF results were then evaluated following the procedures detailed in Zhang et al. (2011). After carefully evaluating the mass spectral profiles, diurnal patterns, and temporal variations in the OA factors and comparing them with other collocated measurements, a five-factor solution was selected for both $\mathrm{PM}_{1}$ and $\mathrm{PM}_{2.5}$. The five factors include four primary factors, i.e., hydrocarbon-like OA (HOA), cooking OA (COA), biomass burning OA (BBOA), coal combustion OA (CCOA), and a secondary factor, oxygenated OA (OOA). More detailed descriptions on the PMF results will be given elsewhere.

\subsection{Data reprocessing}

The size distributions measured by APS were converted to mobility-equivalent size distributions using spherical shape assumptions and an effective particle density of $1.7 \mathrm{~g} \mathrm{~cm}^{-3}$. Note that the designations of $\mathrm{PM}_{10}$ and $\mathrm{PM}_{1}$ are with respect to aerosol aerodynamic diameters, while the corresponding mobility-equivalent cut diameters of the two impactors are approximately 7669 and $767 \mathrm{~nm}$, respectively. For simplicity and consistency, we will continue to refer to them as the $\mathrm{PM}_{10}$ and $\mathrm{PM}_{1}$ based on their aerodynamic diameter. For the case of $\mathrm{PM}_{1}$ measurements, the mobility-equivalent cut diameter is quite near the upper range of the SMPS size range. Considering that the cut diameter of the impactor corresponds to the diameter of aerosol particles in the ambient state (aerosol hygroscopic growth effect needs to be taken into account) and the SMPS measures the size distributions of aerosol particles in the dry state, the SMPS measurements should be able to cover the full size range of $\mathrm{PM}_{1}$. When the SMPS was sampling aerosol particles of $\mathrm{PM}_{10}$, the size distributions measured by SMPS and APS were merged together and truncated to an upper limit of $7669 \mathrm{~nm}$ to provide a full range of particle number size distributions (PNSDs). In addition, the AE33 measures the aerosol absorption coefficient at several wavelengths; the mass concentrations of black carbon (BC) were converted from measured aerosol absorption coefficients at $880 \mathrm{~nm}$ with a mass absorption coefficient of $7.77 \mathrm{~m}^{2} \mathrm{~g}^{-1}$ (Drinovec et al., 2015).

Since group 2 and 3 switched between $\mathrm{PM}_{1}$ and $\mathrm{PM}_{10}$ inlets every $15 \mathrm{~min}$, all measurements were averaged over each 15 min observation episode, resulting in valid time resolutions of $15 \mathrm{~min}$ for APS and BC PM 10 measurements and of $30 \mathrm{~min}$ for SMPS, CV-ToF-ACSM, and the humidified nephelometer system $\mathrm{PM}_{1}$ and $\mathrm{PM}_{10}$ measurements, respectively. This resulted in a $15 \mathrm{~min}$ time lag between the averaged datasets of group 2 and group 3. To match the time of all the measurement data, the measurements of SMPS, ACSM, and the humidified nephelometer system were linearly interpolated to the $15 \mathrm{~min}$ time resolution of the APS data.

\section{Methodology}

\subsection{Calculations of hygroscopicity parameters $\kappa_{\text {sca }}$ and $\kappa$ from measurements of the humidified nephelometer system}

The humidified nephelometer system measures aerosol lightscattering coefficients and backscattering coefficients at three wavelengths under the dry state and $85 \% \mathrm{RH}$ condition, providing measurements of the light-scattering enhancement factor $f(\mathrm{RH}, \lambda)$, which is defined as $f(\mathrm{RH}=85 \%, \lambda)=$ 
Table 1. Densities $(\rho)$ and hygroscopicity parameters $(\kappa)$ of inorganic salts used in this study.

\begin{tabular}{lrrrr}
\hline Species & $\mathrm{NH}_{4} \mathrm{NO}_{3}$ & $\mathrm{NH}_{4} \mathrm{HSO}_{4}$ & $\left(\mathrm{NH}_{4}\right)_{2} \mathrm{SO}_{4}$ & $\mathrm{NH}_{4} \mathrm{Cl}$ \\
\hline$\rho\left(\mathrm{g} \mathrm{cm}^{-3}\right)$ & 1.72 & 1.78 & 1.769 & 1.527 \\
$\kappa$ & 0.58 & 0.56 & 0.48 & 0.93 \\
\hline
\end{tabular}

$\frac{\sigma_{\mathrm{sp}}(\mathrm{RH}, \lambda)}{\sigma_{\mathrm{sp}}(\mathrm{dry}, \lambda)}$, with $\lambda$ being the light wavelength. In this study, we only calculate $f(\mathrm{RH}, 525 \mathrm{~nm})$ and refer to it hereinafter as $f(\mathrm{RH})$ for simplicity. Brock et al. (2016) proposed a single parameter formula to describe $f(\mathrm{RH}, \lambda)$ as a function of RH. Kuang et al. (2017) further developed this parameterization scheme to better describe measured $f(\mathrm{RH})$ by including the reference $\mathrm{RH}\left(\mathrm{RH}_{0}\right)$ in the dry nephelometer as shown in Eq. (1), using which the optical hygroscopicity parameter $\kappa_{\text {sca }}$ can be derived from $f(\mathrm{RH})_{\text {measured }}$ :

$$
\begin{aligned}
& f(\mathrm{RH})_{\text {measured }}= \\
& \quad\left(1+\kappa_{\mathrm{sca}} \frac{\mathrm{RH}}{100-\mathrm{RH}}\right) /\left(1+\kappa_{\mathrm{sca}} \frac{\mathrm{RH}_{0}}{100-\mathrm{RH}_{0}}\right) .
\end{aligned}
$$

An overall hygroscopicity parameter $\kappa$, referred to as $\kappa_{f(\mathrm{RH})}$, can be retrieved from the measured $f(\mathrm{RH})$ with the addition of a simultaneously measured PNSD and BC mass concentration (Chen et al., 2014; Kuang et al., 2017). The idea is to conduct an iterative calculation using the Mie theory and the $\kappa$-Köhler theory together to find a $\kappa_{f}$ (RH) that closes the gap between the simulated and the measured $f(\mathrm{RH})$. Details on the calculations of $\kappa_{f(\mathrm{RH})}$ can be found in Kuang et al. (2017).

\subsection{Calculations of $\kappa_{\text {chem }}$ from aerosol chemical-composition measurements}

For the calculation of aerosol hygroscopicity parameter $\kappa$ based on measured chemical-composition data $\left(\kappa_{\text {chem }}\right)$, detailed information on the chemical species is needed. The $\mathrm{CV}$-ToF-ACSM can only provide bulk mass concentrations of $\mathrm{SO}_{4}^{2-}, \mathrm{NO}_{3}^{-}, \mathrm{NH}_{4}^{+}$, and $\mathrm{Cl}^{-}$ions and organic components. For the inorganic ions, a simplified ion pairing scheme (as listed in Table 1) was used to convert ion mass concentrations to mass concentrations of corresponding inorganic salts (Gysel et al., 2007; Wu et al., 2016).

Mass concentrations of $\mathrm{SO}_{4}^{2-}, \mathrm{NO}_{3}^{-}, \mathrm{NH}_{4}^{+}$, and $\mathrm{Cl}^{-}$are thus specified as ammonium sulfate (AS), ammonium nitrate (AN), ammonium chloride (AC), and ammonium bisulfate (ABS), with the $\kappa$ values of these salts specified according to Wu et al. (2016) and Liu et al. (2014; Table 1). For a given internal mixture of different aerosol chemical species, a simple mixing rule called Zdanovskii-Stokes-Robinson (ZSR) can be used for predicting the overall $\boldsymbol{\kappa}_{\text {chem }}$ on the basis of volume fractions of different chemical species $\left(\varepsilon_{i}\right.$; Petters and Kreidenweis, 2007): $\kappa_{\mathrm{chem}}=\sum_{i} \kappa_{i} \cdot \varepsilon_{i}$,

where $\kappa_{i}$ and $\varepsilon_{i}$ represent the hygroscopicity parameter $\kappa$ and volume fraction of chemical component $i$ in the mixture. Based on Eq. (2), $\boldsymbol{\kappa}_{\text {chem }}$ can be calculated as follows:

$$
\begin{aligned}
\kappa_{\text {chem }} & =\kappa_{\mathrm{AS}} \varepsilon_{\mathrm{AS}}+\kappa_{\mathrm{AN}} \varepsilon_{\mathrm{AN}}+\kappa_{\mathrm{ABS}} \varepsilon_{\mathrm{ABS}}+\kappa_{\mathrm{AC}} \varepsilon_{\mathrm{AC}} \\
& +\kappa_{\mathrm{BC}} \varepsilon_{\mathrm{BC}}+\kappa_{\mathrm{OA}} \varepsilon_{\mathrm{OA}},
\end{aligned}
$$

where $\kappa_{\mathrm{OA}}$ and $\varepsilon_{\mathrm{OA}}$ represent the $\kappa$ and volume fraction of total organics. Since black carbon is hydrophobic, $\kappa_{\mathrm{BC}}$ is assumed to be zero. With known $\kappa_{\text {chem }}, \kappa_{\mathrm{OA}}$ can be calculated using the following formula:

$\kappa_{\mathrm{OA}}=\frac{\kappa_{\mathrm{chem}}-\left(\kappa_{\mathrm{AS}} \varepsilon_{\mathrm{AS}}+\kappa_{\mathrm{AN}} \varepsilon_{\mathrm{AN}}+\kappa_{\mathrm{ABS}} \varepsilon_{\mathrm{ABS}}+\kappa_{\mathrm{AC}} \varepsilon_{\mathrm{AC}}\right)}{\varepsilon_{\mathrm{OA}}}$.

The volume concentration of organics was calculated by assuming that the density of POA is $1 \mathrm{~g} \mathrm{~cm}^{-3}$ and density of OOA is $1.4 \mathrm{~g} \mathrm{~cm}^{-3}$ (Wu et al., 2016). For the calculation of the total volume concentration $\left(V_{\text {tot }}\right)$, we have three approaches. The first approach is to sum up the volume concentrations of all chemical species (AS, AN, ABS, AC, BC, and organics), where the volume concentration of $\mathrm{BC}$ was calculated by assuming a density of $1.7 \mathrm{~g} \mathrm{~cm}^{-3}$ (Wu et al., 2016). We refer to the calculated total volume concentration of aerosol particles as $V_{\text {tot, Chem. }}$. The second approach is to integrate $V_{\text {tot }}$ from the measured PNSD using the equation $V_{\text {tot, PNSD }}=\int \frac{4}{3} \pi r^{3} n(r) \mathrm{d} r$, where $r$ is the particle radius and $n(r)$ is the measured particle number concentrations. The third approach is to use the trained machine-learning estimator to estimate the $V_{\text {tot }}$ based on measurements of the dry nephelometer ( $\left.V_{\text {tot, Neph }}\right)$, as was introduced in Kuang et al. (2018). $V_{\text {tot }}$ values of $\mathrm{PM}_{1}$ calculated using these three methods were compared to each other and shown in Fig. S2 in the Supplement. $V_{\text {tot, Chem }}$ correlates well with $V_{\text {tot, PNSD, }}$ but it is on average $30 \%$ lower than that of $V_{\text {tot, PNSD. Chemi- }}$ cal components within aerosol particles such as dust, sea salt, and metal ions cannot be detected by CV-ToF-ACSM. Since the Gucheng site is far from the ocean, sea salt should have negligible impacts on the total mass of $\mathrm{PM}_{1}$. However, mineral dust can extend into the submicron range (Shao et al., 2007), which might be the cause for the low $V_{\text {tot, Chem }}$ calculated using CV-ToF-ACSM and BC data. $V_{\text {tot, Neph }}$ also correlates well with $V_{\text {tot, PNSD }}$ but is on average $16 \%$ lower than that of $V_{\text {tot, PNSD }}$. Closure studies between modeled and measured $\sigma_{\mathrm{sp}}$ and $\sigma_{\mathrm{bsp}}$ at $525 \mathrm{~nm}$ for $\mathrm{PM}_{1}$ and $\mathrm{PM}_{10}$ aerosol particles all showed good agreement between theoretical modeling results and measurements (Fig. S1), with most points falling within the $20 \%$ relative deviation lines. However, modeled $\sigma_{\mathrm{sp}}$ values for both $\mathrm{PM}_{1}$ and $\mathrm{PM}_{10}$ were obviously higher than measured $\sigma_{\mathrm{sp}}$, with an average relative difference of $22 \%$ and $13 \%$ between them for $\mathrm{PM}_{10}$ and $\mathrm{PM}_{1}$, respectively. The result for $\mathrm{PM}_{1}$ explains why $V_{\text {tot, Neph }}$ was 


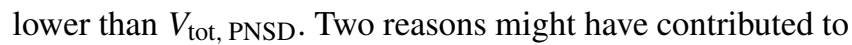
this discrepancy. (1) Both PNSD and aerosol optical property measurements carry non-negligible uncertainties, with the SMPS bearing measurement uncertainty of $30 \%$ for particles larger than $200 \mathrm{~nm}$, which contribute most to $V_{\text {tot }}$ (Wiedensohler et al., 2012), and the nephelometer measured $\sigma_{\mathrm{sp}}$ having an uncertainty of $9 \%$ (Sherman et al., 2015; Titos et al., 2016). (2) The sampling tube length, valves, tube angles, and flow rates are different for the dry nephelometer and SMPS (e.g., much shorter tube and smaller flow rate for SMPS than those for the dry nephelometer), leading to different wall loss and loss in semi-volatile aerosol components. ACSM and the dry nephelometer had a similar tube length, and nephelometer measurements bear less uncertainty than SMPS. Thus, $V_{\text {tot, Neph }}$ was chosen as $V_{\text {tot }}$ in the calculations of Eq. (4). Based on the calculated $V_{\text {tot }}$, the material unidentified by CV-ToF-ACSM accounts for $19 \%$ of $V_{\text {tot }}$ on average, which could not be neglected in the $\kappa_{\mathrm{OA}}$ calculation. Thus, Eq. (4) was modified as follows:

$\kappa_{\mathrm{OA}}=\frac{\kappa_{\mathrm{chem}}-\left(\kappa_{\mathrm{AS}} \cdot \varepsilon_{\mathrm{AS}}+\kappa_{\mathrm{AN}} \cdot \varepsilon_{\mathrm{AN}}+\kappa_{\mathrm{ABS}} \cdot \varepsilon_{\mathrm{ABS}}+\kappa_{X} \cdot \varepsilon_{X}\right)}{\varepsilon_{\mathrm{OA}}}$,

where $\kappa_{X}$ and $\varepsilon_{X}$ are the hygroscopicity parameter $\kappa$ and volume fraction of the unidentified material. Previous studies using $V_{\text {tot, }}$ Chem as the total volume concentration of aerosol particles have avoided the discussion about influences of unidentified material by the CV-ToF-ACSM or other aerosol mass spectrometer instruments. The hygroscopicity of these unidentified materials, which might be dust or other components in continental regions, was not discussed before. Dust is nearly hydrophobic, with mineral dust showing $\kappa$ values in range of 0.01 to 0.08 (Koehler et al., 2009). In this paper, we arbitrarily specified $\kappa_{X}$ to be 0.05 .

\subsection{Can $\kappa_{f(\mathrm{RH})}$ represent $\kappa_{\mathrm{chem}}$ ?}

According to Eq. (5), the measured bulk $\kappa_{\text {chem }}$ values are needed to derive $\kappa_{\mathrm{OA}}$. When bulk aerosol chemical compositions and aerosol hygroscopicity $\kappa_{f(\mathrm{RH})}$ measurements are available, one might naturally jump to the conclusion of treating $\kappa_{f}(\mathrm{RH})$ as $\kappa_{\text {chem }}$ to derive $\kappa_{\mathrm{OA}}$ because both $\kappa_{f}(\mathrm{RH})$ and $\kappa_{\text {chem }}$ are from bulk aerosol measurements. However, the relationship between $\kappa_{\text {chem }}, \kappa_{f}(\mathrm{RH})$ and the size-resolved $\kappa$ distribution needs to be clarified in order to answer the question of whether $\kappa_{f(\mathrm{RH})}$ can accurately represent $\kappa_{\mathrm{chem}}$. The physical meanings of different $\kappa$ representations used in the following discussions are listed in Table 2.

Using $V_{i}$ to represent volume concentrations of chemical species $i$ and $V_{i}\left(D_{\mathrm{p}}\right)$ to represent volume concentrations of species $i$ with a diameter of $D_{\mathrm{p}}, \kappa_{\text {chem }}$ can be derived as follows based on Eq. (2):

$$
\begin{aligned}
\kappa_{\text {chem }} & =\sum_{i} \kappa_{i} \cdot \varepsilon_{i}=\sum_{i} \frac{V_{i}}{V_{\text {tot }}} \cdot \kappa_{i} \\
& =\sum_{i} \frac{1}{V_{\text {tot }}} \cdot \int \frac{\mathrm{d} V_{i}\left(D_{\mathrm{p}}\right)}{\mathrm{d} \log D_{\mathrm{p}}} \cdot \mathrm{d} \log D_{\mathrm{p}} \cdot \kappa_{i} .
\end{aligned}
$$

By swapping the order of summation and integration, Eq. (6) can be written as

$\kappa_{\text {chem }}=\int \frac{1}{V_{\text {tot }}} \cdot \sum_{i} \frac{\mathrm{d} V_{i}\left(D_{\mathrm{p}}\right)}{\mathrm{d} \log D_{\mathrm{p}}} \cdot \mathrm{d} \log D_{\mathrm{p}} \cdot \kappa_{i}$.

Considering that $\kappa_{D_{\mathrm{p}}}=\sum_{i} \frac{\mathrm{d} V_{i}\left(D_{\mathrm{p}}\right)}{\mathrm{d} V\left(D_{\mathrm{p}}\right)} \cdot \kappa_{i}$, Eq. (7) can be rewritten as

$\kappa_{\text {chem }}=\frac{1}{V_{\text {tot }}} \int \kappa_{D_{\mathrm{p}}} \cdot \mathrm{d} V\left(D_{\mathrm{p}}\right)$.

The result of Eq. (8) indicates that $\boldsymbol{\kappa}_{\text {chem }}$ calculated using Eq. (3) represents the overall hygroscopicity of aerosol particles with volume contribution as the weighting function of $\kappa_{D_{\mathrm{p}}}$.

As for $\kappa_{f(\mathrm{RH})}$, a detailed analysis is performed here to facilitate its physical understanding. The differential form of $\sigma_{\mathrm{sp}}$ of aerosol particles in the dry state can be expressed as follows:

$\sigma_{\mathrm{sp}}=\int \frac{\mathrm{d} \sigma_{\mathrm{sp}}}{\mathrm{d} \log D_{\mathrm{p}}} \mathrm{d} \log D_{\mathrm{p}}$.

Based on the definition of $f(\mathrm{RH})$, the $\sigma_{\mathrm{sp}}$ of aerosol particles under different $\mathrm{RH}$ conditions can be written as

$\sigma_{\mathrm{sp}}(\mathrm{RH})=\int \frac{\mathrm{d} \sigma_{\mathrm{sp}}}{\mathrm{d} \log D_{\mathrm{p}}} \cdot f_{D_{\mathrm{p}}}(\mathrm{RH}) \cdot \mathrm{d} \log D_{\mathrm{p}}$.

Therefore, the differential form of observed overall $f(\mathrm{RH})$ can be formulated as

$f(\mathrm{RH})=\int \frac{1}{\sigma_{\mathrm{sp}}} \cdot \frac{\mathrm{d} \sigma_{\mathrm{sp}}}{\mathrm{d} \log D_{\mathrm{p}}} \cdot f_{D_{\mathrm{p}}}(\mathrm{RH}) \cdot \mathrm{d} \log D_{\mathrm{p}}$.

Based on this formula, the sensitivity of $f(\mathrm{RH})$ on the hygroscopicity of aerosol particles with the diameter $D_{\mathrm{p}}$ can be derived as

$\frac{1}{\mathrm{~d} \log D_{\mathrm{p}}} \cdot \frac{\partial f(\mathrm{RH})}{\partial \kappa_{D_{\mathrm{p}}}}=\frac{1}{\sigma_{\mathrm{sp}}} \cdot \frac{\mathrm{d} \sigma_{\mathrm{sp}}}{\mathrm{d} \log D_{\mathrm{p}}} \cdot \frac{\partial f_{D_{\mathrm{p}}}(\mathrm{RH})}{\partial \kappa_{D_{\mathrm{p}}}}$.

The sensitivity of $f(\mathrm{RH})$ to $\kappa_{D_{\mathrm{p}}}$ is determined together by the two terms in Eq. (12): (1) $\frac{1}{\sigma_{\mathrm{sp}}} \cdot \frac{\mathrm{d} \sigma_{\mathrm{sp}}}{\operatorname{d} \log D_{\mathrm{p}}}$, which represents the contribution of $\sigma_{\mathrm{sp}}$ of aerosol particles in the dry state with the diameter $D_{\mathrm{p}}$ to total $\sigma_{\mathrm{sp}}$, and (2) $\frac{\partial f_{D_{\mathrm{p}}}(\mathrm{RH})}{\partial \kappa_{D_{\mathrm{p}}}}$, which represents the sensitivity of $f_{D_{\mathrm{p}}}(\mathrm{RH})$ to $\kappa_{D_{\mathrm{p}}}$. Based on the Mie theory and the $\kappa$-Köhler theory, we simulated the second term under the $85 \% \mathrm{RH}$ condition for varying $D_{\mathrm{p}}$ and 
Table 2. Different $\kappa$ and their physical meanings.

$\kappa_{f(\mathrm{RH})} \quad$ A uniform $\kappa$ for all particle sizes which describes $f(\mathrm{RH})$ accurately

$\kappa_{\text {chem }} \quad$ A bulk $\kappa$ assuming different chemical compositions of aerosol populations are internally mixed and calculated with the ZSR mixing rule

$\kappa_{i} \quad$ hygroscopicity parameter $\kappa$ of chemical species $i$

$\kappa_{D_{\mathrm{p}}} \quad$ The $\kappa$ assuming different chemical compositions of particles with diameter of $D_{\mathrm{p}}$ are internally mixed and calculated with the ZSR mixing rule

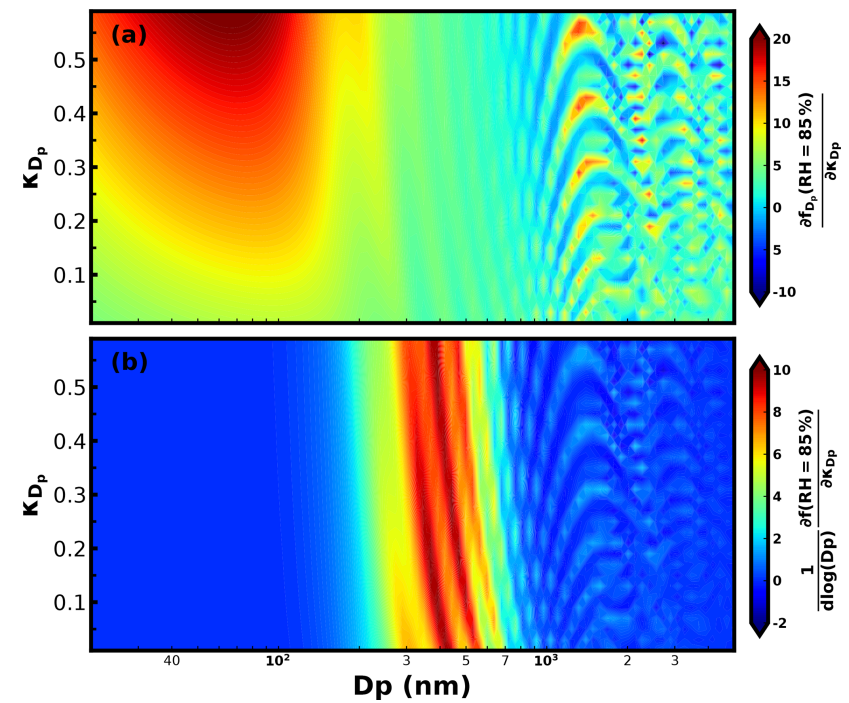

Figure 2. (a) Simulated $\frac{\partial f_{D_{\mathrm{p}}}(\mathrm{RH})}{\partial \kappa_{D_{\mathrm{p}}}}$; (b) simulated $\frac{1}{\operatorname{d} \log D_{\mathrm{p}}} \cdot \frac{\partial f(\mathrm{RH})}{\partial \kappa_{D_{\mathrm{p}}}}$.

$\kappa_{D_{\mathrm{p}}}$ values (Fig. 2a). In the diameter range below $200 \mathrm{~nm}$, $\frac{\partial f_{D_{\mathrm{p}}}(\mathrm{RH})}{\partial \kappa_{D_{\mathrm{p}}}}$ is very high, displaying a maximum near $60 \mathrm{~nm}$. In this diameter range, a larger $\kappa_{D_{\mathrm{p}}}$ generally corresponds to a higher $\frac{\partial f_{D_{\mathrm{p}}}(\mathrm{RH})}{\partial \kappa_{D_{\mathrm{p}}}}$. For $200 \mathrm{~nm}<D_{\mathrm{p}}<800 \mathrm{~nm}$, higher and lower $\frac{\partial f_{D_{\mathrm{p}}}(\mathrm{RH})}{\partial \kappa_{D_{\mathrm{p}}}}$ values appear alternatively, with all values staying positive. For $D_{\mathrm{p}}>800 \mathrm{~nm}$, maxima and minima regions appear alternatively, and $f_{D_{\mathrm{p}}}(\mathrm{RH})$ might decrease with increasing $\kappa_{D_{\mathrm{p}}}$. This is because, at this diameter range, the aerosol scattering efficiency has a non-monotonic response to the particle diameter increase (see Fig. 2a of Kuang et al., 2018).

The first term of Eq. (9), representing size-resolved $\sigma_{\mathrm{sp}}$ contributions of particles with the diameter in the dry state, mainly depends on the PNSD. The average PNSD of $\mathrm{PM}_{10}$ was applied in the simulation of the first term using Mie theory (Fig. S3). Combining results of the first term and second term, the sensitivity of $f(\mathrm{RH})$ to $\kappa_{D_{\mathrm{p}}}$ was obtained and depicted in Fig. 2b. Results reveal that $f(\mathrm{RH})$ is quite sensitive to the $\kappa_{D_{\mathrm{p}}}$ of particles within the 200 to $800 \mathrm{~nm}$ diameter range but almost insensitive to $\kappa_{D_{\mathrm{p}}}$ of particles with diameters below $200 \mathrm{~nm}$ and above $800 \mathrm{~nm}$ (corresponding aerodynamic diameter of about $1 \mu \mathrm{m}$ ). For particles smaller than $200 \mathrm{~nm}$, the first term was quite small, especially for particles smaller than $100 \mathrm{~nm}$ (Fig. S3), while for particles larger than $800 \mathrm{~nm}$, in addition to a small first term, the second term fluctuated between negative and positive values, which is why $f(\mathrm{RH})$ was not sensitive to the overall hygroscopicity of these larger aerosol particles. These results suggest that although $\kappa_{f(\mathrm{RH})}$ was derived from $f(\mathrm{RH})$ measurements of $\mathrm{PM}_{10}$, it mainly represents the overall hygroscopicity of aerosol particles with dry diameters between 200 and $800 \mathrm{~nm}$ for continental aerosol. This result indicates that $\kappa_{f(\mathrm{RH})}$ values derived from $f(\mathrm{RH})$ measurements of $\mathrm{PM}_{10}$ and $\mathrm{PM}_{1}$ should differ little from each other for measurements conducted in continental regions.

However, the quantitative relationship between the $\kappa_{f}(\mathrm{RH})$ and size-resolved $\kappa_{D_{\mathrm{p}}}$ is still not clear. Based on Eq. (11), $f_{D_{\mathrm{p}}}(\mathrm{RH})$ can be expressed as

$$
\begin{aligned}
f_{D_{\mathrm{p}}}(\mathrm{RH}) & =\frac{\mathrm{d} \sigma_{\mathrm{sp}}(\mathrm{RH})}{\mathrm{d} \sigma_{\mathrm{sp}}} \\
& =\frac{\frac{1}{4} \cdot \pi \cdot\left(D_{\mathrm{p}} \cdot g\right)^{2} \cdot Q_{\mathrm{sca}}\left(D_{\mathrm{p}}, g\right) \cdot \mathrm{d} N}{\mathrm{~d} \sigma_{\mathrm{sp}}},
\end{aligned}
$$

where $g$ is the growth factor of aerosol particles which is a function of $\kappa_{D_{\mathrm{p}}}$ and RH (Brock et al., 2016), i.e., $g=$ $\left(1+\kappa_{D_{\mathrm{p}}} \cdot \frac{\mathrm{RH}}{100-\mathrm{RH}}\right)^{1 / 3}, \mathrm{~d} N$ is differential form of aerosol number concentration, and $Q_{\text {sca }}$ is the scattering efficiency as a function of $D_{\mathrm{p}}$ and $g$. The results of Kuang et al. (2018) indicate that, under the dry state, $Q_{\text {sca }}$ can be expressed as $Q_{\text {sca }}=k \cdot D_{\mathrm{p}}$, with $k$ varying as a function of $D_{\mathrm{p}}$. Here, we follow this idea and express the $Q_{\text {sca }}$ under the humidified condition as $Q_{\text {sca }}\left(D_{\mathrm{p}}, g\right)=C \cdot D_{\mathrm{p}} \cdot g$, where $C$ is a function of $D_{\mathrm{p}}, \kappa_{D_{\mathrm{p}}}$, and RH. Replacing $g$ and $Q_{\text {sca }}$ in Eq. (13), we yield

$f_{D_{\mathrm{p}}}(\mathrm{RH})=\frac{\frac{1}{4} \cdot \pi \cdot D_{\mathrm{p}}^{3} \cdot C\left(D_{\mathrm{p}}, \kappa_{D_{\mathrm{p}}}, \mathrm{RH}\right) \cdot\left(1+\kappa_{D_{\mathrm{p}}} \cdot \frac{\mathrm{RH}}{100-\mathrm{RH}}\right) \cdot \mathrm{d} N}{\mathrm{~d} \sigma_{\mathrm{sp}}}$,

which we can substitute into Eq. (8) to obtain a new expression for $f(\mathrm{RH})$ :

$f(\mathrm{RH})=\int \frac{\frac{1}{4} \cdot \pi \cdot D_{\mathrm{p}}^{3} \cdot C\left(D_{\mathrm{p}}, \kappa_{D_{\mathrm{p}}}, \mathrm{RH}\right) \cdot\left(1+\kappa_{D_{\mathrm{p}}} \cdot \frac{\mathrm{RH}}{100-\mathrm{RH}}\right) \cdot \mathrm{d} N}{\sigma_{\mathrm{sp}}}$

If we define $X_{c}\left(D_{\mathrm{p}}, \kappa_{D_{\mathrm{p}}}, \mathrm{RH}\right)=C\left(D_{\mathrm{p}}, \kappa_{D_{\mathrm{p}}}, \mathrm{RH}\right) / k$, and considering that $\mathrm{d} \sigma_{\mathrm{sp}}=\frac{1}{4} \cdot \pi \cdot D_{\mathrm{p}}^{2} \cdot Q_{\mathrm{sca}} \cdot \mathrm{d} N=\frac{1}{4} \cdot \pi \cdot D_{\mathrm{p}}^{3} \cdot k \cdot \mathrm{d} N$, Eq. (14) can be written as

$f(\mathrm{RH})=\int \frac{X_{c}\left(D_{\mathrm{p}}, \kappa_{D_{\mathrm{p}}}, \mathrm{RH}\right) \cdot\left(1+\kappa_{D_{\mathrm{p}}} \cdot \frac{\mathrm{RH}}{100-\mathrm{RH}}\right) \cdot \mathrm{d} \sigma_{\mathrm{sp}}}{\sigma_{\mathrm{sp}}}$.

The $\kappa_{f(\mathrm{RH})}$ is a uniform $\kappa$ for aerosol particle sizes that can yield a simulated $f(\mathrm{RH})$ equal to the measured one. Thus, 
$f(\mathrm{RH})$ can also be expressed as

$f(\mathrm{RH})=\int \frac{X_{c}\left(D_{\mathrm{p}}, \kappa_{f(\mathrm{RH})}, \mathrm{RH}\right) \cdot\left(1+\kappa_{f(\mathrm{RH})} \cdot \frac{\mathrm{RH}}{100-\mathrm{RH}}\right) \cdot \mathrm{d} \sigma_{\mathrm{sp}}}{\sigma_{\mathrm{sp}}}$.

Combining Eqs. (16) and (17), the relationship between $\kappa_{f(\mathrm{RH})}$ and size-resolved $\kappa_{D_{\mathrm{p}}}$ can be derived as

$$
\begin{aligned}
\kappa_{f(\mathrm{RH})} & =\frac{\int X_{c}\left(D_{\mathrm{p}}, \kappa_{D_{\mathrm{p}}}, \mathrm{RH}\right) \cdot \kappa_{D_{\mathrm{p}}} \cdot \mathrm{d} \sigma_{\mathrm{sp}}}{\int X_{c}\left(D_{\mathrm{p}}, \kappa_{f(\mathrm{RH})}, \mathrm{RH}\right) \cdot \mathrm{d} \sigma_{\mathrm{sp}}} \\
& +\frac{\int\left(X_{c}\left(D_{\mathrm{p}}, \kappa_{D_{\mathrm{p}}}, \mathrm{RH}\right)-X_{c}\left(D_{\mathrm{p}}, \kappa_{f(\mathrm{RH})}, \mathrm{RH}\right)\right) \cdot \mathrm{d} \sigma_{\mathrm{sp}}}{\int X_{c}\left(D_{\mathrm{p}}, \kappa_{f(\mathrm{RH})}, \mathrm{RH}\right) \cdot \mathrm{d} \sigma_{\mathrm{sp}}} \\
& \cdot \frac{100-\mathrm{RH}}{\mathrm{RH}} .
\end{aligned}
$$

$X_{c}$ values under $85 \% \mathrm{RH}$ for different $D_{\mathrm{p}}$ and $\kappa_{D_{\mathrm{p}}}$ values are simulated and shown in Fig. 3; based on this result of $X_{c}$ the second term of Eq. (18) (which depends on the PNSD and size-resolved $\kappa_{D_{\mathrm{p}}}$ ) could be calculated using the average PNSD during this field campaign and two assumed extreme cases of size-resolved $\kappa_{D_{\mathrm{p}}}$ (solid and dashed black lines in Fig. 3). For $\mathrm{PM}_{1}$, the second term corresponding to the two size-resolved $\kappa_{D_{\mathrm{p}}}$ cases was -0.007 and 0.008 , respectively. Corresponding values simulated for $\mathrm{PM}_{10}$ were -0.005 and 0.004 , respectively. To further investigate the possible contribution range of the second term to $\kappa_{f(\mathrm{RH})}$, size-resolved $\kappa_{D_{\mathrm{p}}}$ values derived by Liu et al. (2014) based on size-resolved chemical-composition measurements in ambient atmosphere in the NCP region (Fig. S4) were used with the average PNSD during this campaign to calculate values of the second term. Calculated values of second term ranged from -0.005 to 0.009 , with its contribution to $\kappa_{f}(\mathrm{RH})$ ranging from $-1.5 \%$ to $2 \%(0.3 \%$ on average $)$. These results indicate that the second term was negligible in most cases, and Eq. (18) could be approximated as

$\kappa_{f(\mathrm{RH})} \approx \frac{\int X_{c}\left(D_{\mathrm{p}}, \kappa_{D_{\mathrm{p}}}, \mathrm{RH}\right) \cdot \kappa_{D_{\mathrm{p}}} \cdot \mathrm{d} \sigma_{\mathrm{sp}}}{\int X_{c}\left(D_{\mathrm{p}}, \kappa_{f(\mathrm{RH})}, \mathrm{RH}\right) \cdot \mathrm{d} \sigma_{\mathrm{sp}}}$.

$X_{c}$ values shown in Fig. 3 indicate that for aerosol particles in the diameter range of 200 to $800 \mathrm{~nm}$ (which contribute most to $\sigma_{\mathrm{sp}}$ and are the part of the aerosol population that $\kappa_{f}(\mathrm{RH})$ is most sensitive to) and for the observed $\kappa_{D_{\mathrm{p}}}$ range of continental aerosol ( $\kappa_{D_{\mathrm{p}}}$ usually less than 0.5$), X_{c}$ mainly ranged from 0.7 to 1 . Considering this, we might approximately assume $X_{c}$ in Eq. (18) to be a constant value. Then, Eq. (19) can be further simplified to

$\kappa_{f(\mathrm{RH})} \approx \frac{1}{\sigma_{\mathrm{sp}}} \int \kappa_{D_{\mathrm{p}}} \cdot \mathrm{d} \sigma_{\mathrm{sp}}$.

This result suggests that $\kappa_{f(\mathrm{RH})}$ can be approximately understood as the overall hygroscopicity of aerosol particles with the $\sigma_{\mathrm{sp}}$ contribution as the weighting function of $\kappa_{D_{\mathrm{p}}}$.

Based on results of Eqs. (8) and (20), both $\kappa_{f}(\mathrm{RH})$ and $\boldsymbol{\kappa}_{\text {chem }}$ represent the overall hygroscopicity of bulk aerosol

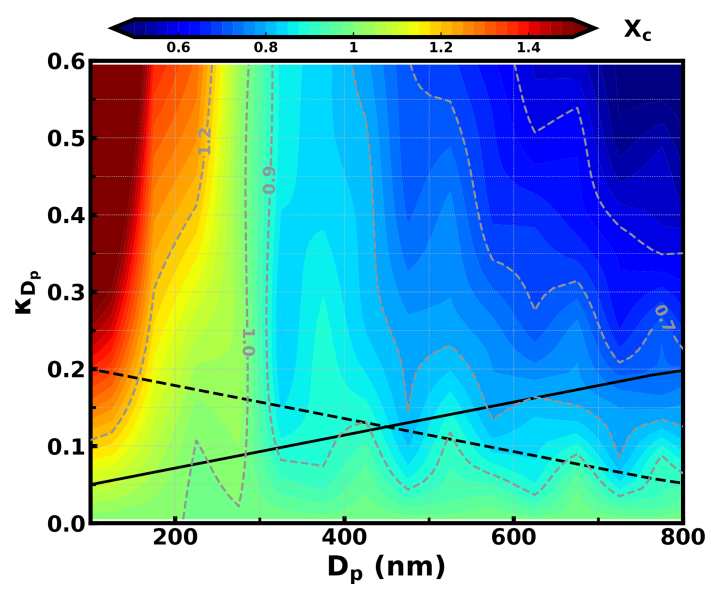

Figure 3. Simulated values of $X_{c}$ under $85 \% \mathrm{RH}$ for different $D_{\mathrm{p}}$ and $\kappa_{D_{\mathrm{p}}}$ values. Black solid and dashed lines are two assumed sizeresolved $\kappa_{D_{\mathrm{p}}}$ distributions.

particles; however, their weighting functions of $\kappa_{D_{\mathrm{p}}}$ are different. Within a certain $D_{\mathrm{p}}$ range, aerosol $\sigma_{\mathrm{sp}}$ is approximately proportional to aerosol volume (Kuang et al., 2018), resulting in little difference between $\kappa_{f(\mathrm{RH})}$ and $\boldsymbol{\kappa}_{\text {chem }}$. In this study, bulk $\kappa_{f(\mathrm{RH})}$ was measured for both $\mathrm{PM}_{1}$ and $\mathrm{PM}_{10}$. How much does $\kappa_{\text {chem }}$ differ from $\kappa_{f(\mathrm{RH})}$ for $\mathrm{PM}_{1}$ and $\mathrm{PM}_{10}$ samples? Both PNSD and size-resolved $\kappa_{D_{\mathrm{p}}}$ distributions contribute to the difference between $\kappa_{\text {chem }}$ and $\kappa_{f}(\mathrm{RH})$. To study their influences in a simple and apparent way, $\boldsymbol{\kappa}_{\text {chem }}$ and $\kappa_{f}(\mathrm{RH})$ were simulated based on the two extreme cases of size-resolved $\kappa_{D_{\mathrm{p}}}$ distributions in Fig. 3 and five average PNSDs corresponding to five ranges of the aerosol Angström exponent $(0.9-1.1,1.1-1.3,1.3-1.5,1.5-1.7$, and 1.7-1.9) during this field campaign. In the instance of $\mathrm{PM}_{1}$, as can be seen in Fig. 4a, assuming a $\kappa_{D_{\mathrm{p}}}$ increasing as a function of $D_{\mathrm{p}}$ resulted in $\kappa_{\text {chem }}<\kappa_{f(\mathrm{RH})}$ (squares in Fig. 4a), especially for PNSDs corresponding to larger Ångström exponents. This is because the volume contributions of small particles (e.g., particles with $D_{\mathrm{p}}$ between 100 to $300 \mathrm{~nm}$ ) to $V_{\text {tot }}$ are larger than their light-scattering coefficient contributions to $\sigma_{\mathrm{sp}}$ (as shown in Fig. S6); thus the hygroscopicity of small particles had larger impacts on $\kappa_{\text {chem }}$ than $\kappa_{f(\mathrm{RH})}$. Higher Ångström exponents generally correspond to a shift in PNSD towards smaller $D_{\mathrm{p}}$, which exacerbates the contribution of small particles, further increasing the difference between $\boldsymbol{\kappa}_{\text {chem }}$ and $\kappa_{f(\mathrm{RH})}$. For the case with $\kappa_{D_{\mathrm{p}}}$ decreasing as a function of $D_{\mathrm{p}}$ (circle markers in Fig. 4a), the opposite applies, resulting in $\kappa_{\text {chem }}>\kappa_{f(\mathrm{RH})}$. In general, for these two extreme cases of size-resolved $\kappa_{D_{\mathrm{p}}}$ distributions, the absolute value of the relative difference between $\boldsymbol{\kappa}_{\text {chem }}$ and $\kappa_{f}(\mathrm{RH})$ ranged from $2.8 \%$ to $7.5 \%$, with an average of $4.8 \%$. This result indicates that for $\mathrm{PM}_{1}, \kappa_{\text {chem }}$ might differ little from $\kappa_{f(\mathrm{RH})}$, since $\kappa_{D_{\mathrm{p}}}$ usually varies less with $D_{\mathrm{p}}$ in ambient atmosphere than in the two assumed cases (Liu et al., 2014). The average sizeresolved $\kappa_{D_{\mathrm{p}}}$ distribution from the Haze in China campaign 
(Liu et al., 2014) indicates that $\kappa_{D_{\mathrm{p}}}$ varies significantly for $D_{\mathrm{p}}<250 \mathrm{~nm}$, while it varies less within the diameter range of $250 \mathrm{~nm}$ to $1 \mu \mathrm{m}$. To further study the variation range of the relative difference between $\boldsymbol{\kappa}_{\text {chem }}$ and $\kappa_{f(\mathrm{RH})}$ under ambient conditions, the size-resolved $\kappa_{D_{\mathrm{p}}}$ distributions derived from measured size-resolved chemical compositions in the NCP region (Liu et al., 2014; shown in Fig. S5) were used in simulations, and results are shown in Fig. 4b. The absolute value of the relative difference between $\boldsymbol{\kappa}_{\text {chem }}$ and $\kappa_{f(\mathrm{RH})}$ ranged from $0.04 \%$ to $8 \%$, with an average and standard deviation of $2.8 \pm 2 \%$, which further confirms that for $\mathrm{PM}_{1}, \kappa_{f}$ (RH) can accurately represent $\boldsymbol{\kappa}_{\text {chem }}$ in most cases.

For $\mathrm{PM}_{10}$, values of $\boldsymbol{\kappa}_{\text {chem }}$ and $\kappa_{f}(\mathrm{RH})$ using $\kappa_{D_{\mathrm{p}}}$ size distributions derived from ambient measurements (Fig. S5, similar to Fig. 4b) were simulated and displayed in Fig. 4c. The simulated absolute values of the relative difference between $\kappa_{\text {chem }}$ and $\kappa_{f(\mathrm{RH})}$ ranged from $0.2 \%$ to $41 \%$, with an average and standard deviation of $16 \pm 8 \%$ and with all $\kappa_{\text {chem }}$ values lower than $\kappa_{f(\mathrm{RH})}$. This is because, for $\mathrm{PM}_{10}$, supermicron particles, typically with low hygroscopicity (Fig. S5), contribute much more to $V_{\text {tot }}$ than to $\sigma_{\mathrm{sp}}$ (as shown in Fig. S7). These results indicate that, for $\mathrm{PM}_{10}, \kappa_{f(\mathrm{RH})}$ cannot accurately represent $\boldsymbol{\kappa}_{\text {chem }}$.

Above analysis results indicate that $\kappa_{f(\mathrm{RH})}$ retrieved from light-scattering measurements of $\mathrm{PM}_{1}$ represent the $\boldsymbol{\kappa}_{\text {chem }}$ of $\mathrm{PM}_{1}$ accurately and can be used in Eq. (5) as measured $\boldsymbol{\kappa}_{\text {chem }}$ for deriving $\kappa_{\mathrm{OA}}$.

\section{Results and discussions}

\subsection{Overview of the campaign data}

The time series of ambient RH, chemical compositions of $\mathrm{PM}_{2.5}$ and $\mathrm{PM}_{1}, \sigma_{\mathrm{sp}}$ at $525 \mathrm{~nm}$ of $\mathrm{PM}_{10}$ and $\mathrm{PM}_{1}$ in the dry state, and calculated $\kappa_{\mathrm{sca}}$ and $\kappa_{f(\mathrm{RH})}$ values of $\mathrm{PM}_{10}$ and $\mathrm{PM}_{1}$ are shown in Fig. 5. Overall, the mass concentrations of NR-PM ${ }_{1}$ and NR-PM 2.5 ranged from 1 to $221 \mu \mathrm{g} \mathrm{m}^{-3}$ and from 1.8 to $326 \mu \mathrm{g} \mathrm{m}^{-3}$, with average concentrations of 63 and $93 \mu \mathrm{g} \mathrm{m}^{-3}$, respectively. Measured $\sigma_{\mathrm{sp}}$ at $525 \mathrm{~nm}$ of $\mathrm{PM}_{1}$ and $\mathrm{PM}_{10}$ ranged from 11 to $1875 \mathrm{Mm}^{-1}$ and from 18 to $2732 \mathrm{Mm}^{-1}$, with average values of 550 and $814 \mathrm{Mm}^{-1}$, respectively. These results demonstrate that this campaign was carried out at a site that is overall highly polluted, where quite clean conditions as well as extremely polluted conditions were experienced during the measurement period. The mass contributions of ammonium, nitrate, sulfate, and organics to NR-PM 2.5 and NR-PM 1 are listed in Table 3, with organics being the major fraction of NR-PM 1 and NR-PM 2.5 .

During Period 1 shown in Fig. 5, nitrate contributed most to inorganics, while inorganics contribute most to mass concentrations of NR-PM 2.5 and NR-PM 1 . During Period 2, shown in Fig. 5, the ambient RH is relatively lower than that of the first period, ranging from $16 \%$ to $86 \%$ with an average of $49 \%$. During this period, organics contributed most to mass concentrations of NR-PM 2.5 and NR-PM 1 , with the NR mass concentrations of $\mathrm{PM}_{2.5}$ and $\sigma_{\mathrm{sp}}$ at $525 \mathrm{~nm}$ of $\mathrm{PM}_{10}$ being only $33 \%$ and $40 \%$ higher than those of $\mathrm{PM}_{1}$.

The time series of calculated $\kappa_{\text {sca }}$ and $\kappa_{f(\mathrm{RH})}$ are shown in Fig. 5e-f. The $\kappa_{\text {sca }}$ of $\mathrm{PM}_{1}$ and $\mathrm{PM}_{10}$ ranged from 0.01 to 0.2 and from 0.02 to 0.17 , with corresponding averages of 0.09 and 0.08 , respectively. The $\kappa_{f(\mathrm{RH})}$ was not available from 12:00 on 10 December to 12:00 LT on 11 December due to the absence of PNSD measurements. The $\kappa_{f(\mathrm{RH})}$ of $\mathrm{PM}_{1}$ and $\mathrm{PM}_{10}$ ranged from 0.02 to 0.27 and from 0.03 to 0.26 , with corresponding averages of 0.12 and 0.12 , respectively. These results indicate that the hygroscopicity during this campaign was generally low, which could be associated with the high mass contributions of organics. The range as well as the average level of $\kappa_{f}(\mathrm{RH})$ is quite consistent with the results obtained at the same site in winter 2016, suggesting the prevalent low aerosol hygroscopicity conditions in winter at this site. Additionally, it can be noted that, except for fog events, $\kappa_{\text {sca }}$ and $\kappa_{f(\mathrm{RH})}$ values of $\mathrm{PM}_{1}$ are generally higher than those of $\mathrm{PM}_{10}$, yet the differences are small (10\% and $3.5 \%$ for $\kappa_{\text {sca }}$ and $\kappa_{f(\mathrm{RH})}$, respectively). Although particles with diameters above $800 \mathrm{~nm}$ have an almost negligible impact on retrieved $\kappa_{f(\mathrm{RH})}$ (refer to discussions in Sect. 3.3), it can still cause a small difference between $\kappa_{f(\mathrm{RH})}$ of $\mathrm{PM}_{10}$ and $\mathrm{PM}_{1}$. Results of previous studies indicate that the overall hygroscopicity of aerosol particles larger than $800 \mathrm{~nm}$ is usually low and is typically lower than the overall hygroscopicity of accumulation-mode particles (Liu et al., 2014), which may explain why $\kappa_{f(\mathrm{RH})}$ values of $\mathrm{PM}_{1}$ are generally higher than those of $\mathrm{PM}_{10}$ during non-fog periods (periods with $\mathrm{RH}<100 \%$ ).

During fog periods, a large number of submicron particles in the dry state will be activated into fog droplets, which are supermicron particles in the ambient state (see PNSD examples in Fig. S4a), exerting substantial impacts on $f(\mathrm{RH})$ measurements of $\mathrm{PM}_{10}$, which are not detectable in the $\mathrm{PM}_{1}$ measurements. Since for a certain particle diameter and fog supersaturation, particles with higher hygroscopicity are more readily activated, the observed $\mathrm{PM}_{10} \kappa_{f(\mathrm{RH})}$ increased during fog events and often exceeded those of $\mathrm{PM}_{1}$ in contrast to non-fog periods (Fig. 5f).

\section{2 $\kappa_{\mathrm{OA}}$ derivations and its relationship with organic aerosol oxidation state}

The results in Sect. 3.3 demonstrate that the $\kappa_{f(\mathrm{RH})}$ of $\mathrm{PM}_{1}$ accurately represents the $\kappa_{\text {chem }}$ in most cases; thus a closure study between calculated $\kappa_{\text {chem }}$ values of $\mathrm{PM}_{1}$ based on measured chemical compositions and measured $\boldsymbol{\kappa}_{\text {chem }}$ values (represented by $\mathrm{PM}_{1} \kappa f(\mathrm{RH})$ ) can be conducted using Eq. (3) if $\kappa_{\mathrm{OA}}$ is known. A $\kappa_{\mathrm{OA}}$ of 0.06 was used in this closure test, which was calculated by Wu et al. (2016) based on aerosol chemical composition and aerosol hygroscopicity measurements. As shown in Fig. 6a, the comparison between measured and calculated $\kappa_{\text {chem }}$ has not achieved very good agree- 

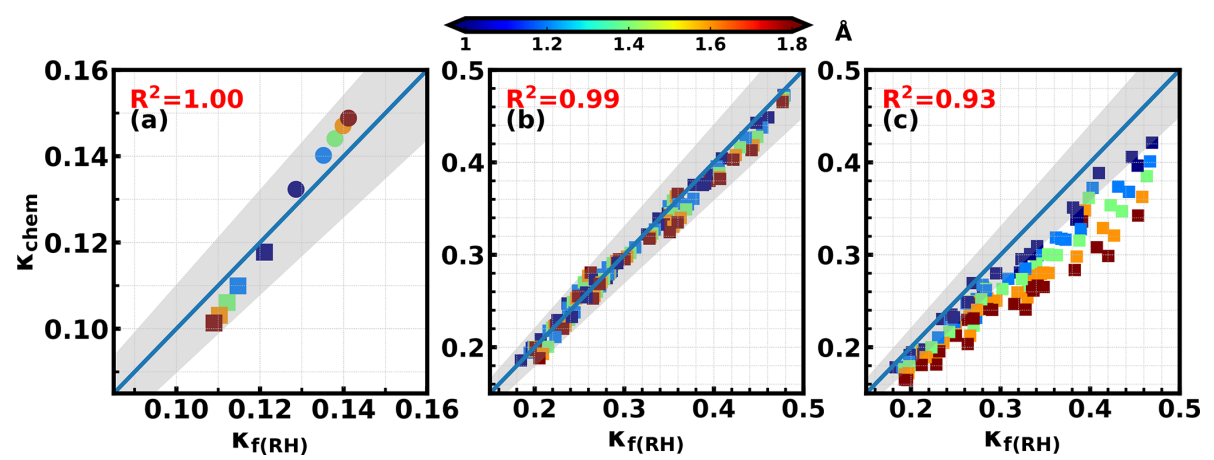

Figure 4. $\kappa_{\text {chem }}$ versus $\kappa_{f(\mathrm{RH})}$; colors represent average $\AA$ Angström exponent $(\AA)$ values of corresponding PNSD (a) corresponding to sizeresolved $\kappa_{D_{\mathrm{p}}}$ distributions shown in Fig. 3 (squares correspond to the solid line in Fig. 3, and circles correspond to the dashed line in Fig. 3 ). (b) and (c) correspond to size-resolved $\kappa_{D_{\mathrm{p}}}$ distributions shown in Fig. S4 for $\mathrm{PM}_{1}$ and $\mathrm{PM}_{10}$, respectively. Gray areas represent the absolute relative differences between $\boldsymbol{\kappa}_{\text {chem }}$ and $\kappa_{f(\mathrm{RH})}$ less than $10 \%$.

Table 3. Average (range) mass contribution of ammonium, nitrate, sulfate, and organics to NR-PM 2.5 and NR-PM 1 during different periods.

\begin{tabular}{|c|c|c|c|c|c|c|c|c|}
\hline \multirow[t]{2}{*}{ Species } & \multicolumn{2}{|c|}{ Ammonium } & \multicolumn{2}{|c|}{ Nitrate } & \multicolumn{2}{|c|}{ Sulfate } & \multicolumn{2}{|c|}{ Organics } \\
\hline & $\mathrm{PM}_{1}$ & $\mathrm{PM}_{2.5}$ & $\mathrm{PM}_{1}$ & $\mathrm{PM}_{2.5}$ & $\mathrm{PM}_{1}$ & $\mathrm{PM}_{2.5}$ & $\mathrm{PM}_{1}$ & $\mathrm{PM}_{2.5}$ \\
\hline \multirow[t]{2}{*}{ Entire period } & $12 \%$ & $12 \%$ & $13 \%$ & $14 \%$ & $10 \%$ & $11 \%$ & $59 \%$ & $59 \%$ \\
\hline & $0.2 \%-24 \%$ & $0.1 \%-24 \%$ & $2 \%-31 \%$ & $1 \%-32 \%$ & $0.3 \%-49 \%$ & $0.2 \%-50 \% \%$ & $12 \%-99 \%$ & $4 \%-91 \%$ \\
\hline Period 1 & $15 \%$ & $16 \%$ & $22 \%$ & $24 \%$ & $13 \%$ & $14 \%$ & $47 \%$ & $42 \%$ \\
\hline Fog & $10 \%-17 \%$ & $12 \%-18 \%$ & $11 \%-28 \%$ & $16 \%-30 \%$ & $9 \%-15 \%$ & $12 \%-16 \%$ & $30 \%-65 \%$ & $37 \%-55 \%$ \\
\hline Period 1 & $17 \%$ & $16 \%$ & $23 \%$ & $23 \%$ & $12 \%$ & $12 \%$ & $43 \%$ & $44 \%$ \\
\hline Non-fog & $10 \%-22 \%$ & $7 \%-21 \%$ & $6 \%-31 \%$ & $5 \%-32 \%$ & $8 \%-23 \%$ & $7 \%-17 \%$ & $32 \%-75 \%$ & $31 \%-69 \%$ \\
\hline \multirow[t]{2}{*}{ Period 2} & $12 \%$ & $10 \%$ & $11 \%$ & $10 \%$ & $8 \%$ & $7 \%$ & $64 \%$ & $67 \%$ \\
\hline & $0.2 \%-20 \%$ & $0.1 \%-19 \%$ & $5 \%-30 \%$ & $4 \%-29 \%$ & $0.3 \%-16 \%$ & $0.2 \%-16 \%$ & $40 \%-82 \%$ & $40 \%-85 \%$ \\
\hline
\end{tabular}

ments. We notice that the calculated $\kappa_{\text {chem }}$ was overestimated when the mass fraction of organic aerosol ( $\left.f_{\mathrm{OA}}\right)$ was lower than $45 \%$, while it was underestimated when $\mathrm{f}_{\mathrm{OA}}$ was higher than $45 \%$. As described in Sect. 4.1, these two situations roughly correspond to Period 1 and 2, respectively. Separating the data points shown in Fig. 6a into Period 1 (Fig. 7b) and 2 (Fig. $7 \mathrm{c}$ ), it can be seen that all low $\mathrm{f}_{\mathrm{OA}}$ data points are found in Period 1, with most of the data points showing a $\mathrm{f}_{\mathrm{OA}}$ of less than $50 \%$. Although the calculated $\boldsymbol{\kappa}_{\text {chem }}$ values during this period were on average $25 \%$ higher than the measured $\kappa_{\text {chem }}$ values, they were highly correlated $(R=0.84)$. A similar case was also found in Wu et al. (2013), and they concluded that the loss of semi-volatile ammonium nitrate in the HTDMA might be the reason. The relationship between nitrate concentration and the difference between calculated and measured $\boldsymbol{\kappa}_{\text {chem }}$ were investigated, which confirmed the influence of nitrate on this discrepancy (Fig. S7) and the overestimation of calculated $\boldsymbol{\kappa}_{\text {chem }}$ due to the volatile loss of ammonium nitrate. Since the tube length (from the splitter to inlet of instrument) of the wet nephelometer was about $1 \mathrm{~m}$ longer than that of the CV-ToF-ACSM, there was probably more loss in ammonium nitrate in the wet nephelometer.
During Period 2, the average mass fraction of nitrate was low $(11 \%)$, and the loss of ammonium nitrate had a minor influence on $\boldsymbol{\kappa}_{\text {chem }}$ estimations (Fig. S7). However, when organic aerosol was dominant during Period 2, the calculated $\boldsymbol{\kappa}_{\text {chem }}$ was underestimated in most cases (Fig. 6c). Previous studies have shown a larger $\kappa_{\mathrm{OA}}$ for OA with a higher oxidation level (Chang et al., 2010; Duplissy et al., 2011; Wu et al., 2013), which might have contributed to the underestimation in $\kappa_{\text {chem. }}$. This gave us the hint that Period 2 might provide us a good opportunity to study $\kappa_{\mathrm{OA}}$. Following the method in Sect. 3.2, $\kappa_{\mathrm{OA}}$ was derived using Eq. (5), resulting in a $\kappa_{\mathrm{OA}}$ ranging from 0.0 to 0.25 , with an average of $0.08 \pm 0.06$. This indicates that using a constant $\kappa_{\mathrm{OA}}$ value in the calculation of $\kappa_{\text {chem }}$ would result in a large bias. To further investigate the impact of OA oxidation level on $\kappa_{\mathrm{OA}}$, we compared the derived $\kappa_{\mathrm{OA}}$ against $\mathrm{f}_{44}$, which is often used to represent the oxidation level of OA. Results show a clear positive correlation $(R=0.79)$ and a statistical relationship of $\kappa_{\mathrm{OA}}=1.04 \cdot f_{44}-0.02$ (Fig. 7a), indicating that the degree of the oxidation level is a crucial parameter determining the OA hygroscopicity. Based on the relationship between $f_{44}$ and the O/C ratio for CV-ACSM (Hu et al., 


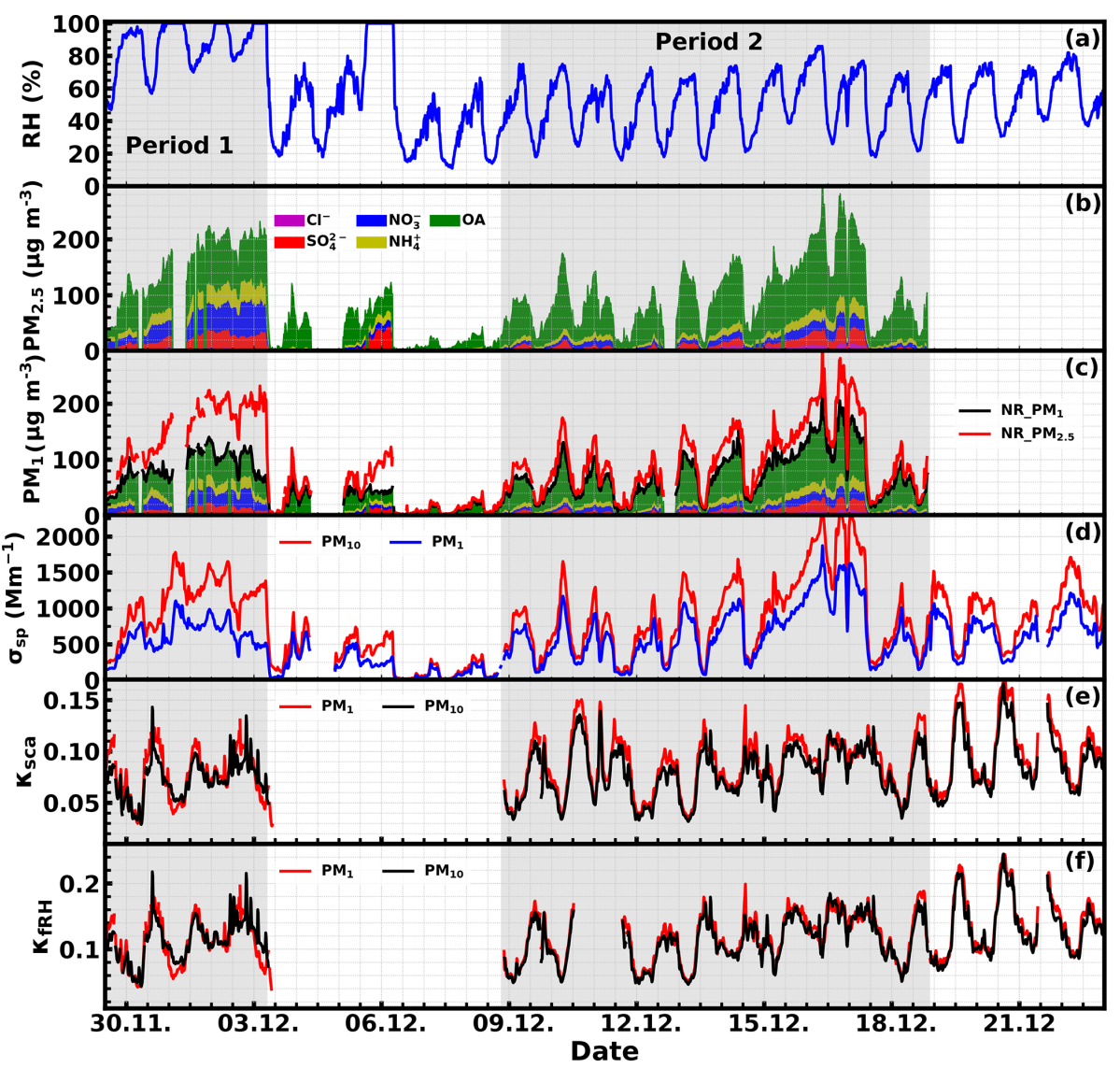

Figure 5. Time series of ambient RH (a), chemical compositions of $\mathrm{PM}_{2.5}$ (b) and $\mathrm{PM}_{1}(\mathbf{c}), \sigma_{\mathrm{sp}}$ at $525 \mathrm{~nm}$ of $\mathrm{PM}_{10}$ and $\mathrm{PM}_{1}(\mathbf{d})$, and calculated $\kappa_{\text {sca }}(\mathbf{e})$ and $\kappa_{f(\mathrm{RH})}(\mathbf{f})$ values of $\mathrm{PM}_{10}$ and $\mathrm{PM}_{1}$.

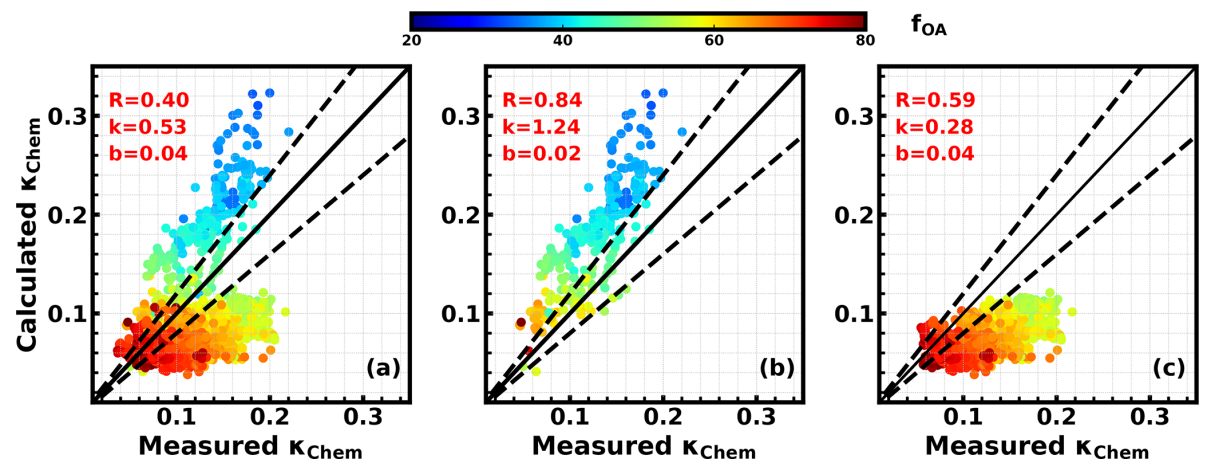

Figure 6. Comparison between measured and calculated $\kappa_{\mathrm{chem}}$ by assuming a $\kappa_{\mathrm{OA}}$ of 0.06 . (a) The whole period. (b) Only Period 1 . (c) Only Period 2. Colors represents the mass fractions of organic aerosol in NR-PM $\left(f_{\mathrm{OA}}\right)$, and the color bar is shown on the top.

2018b), $\mathrm{O}: \mathrm{C}=3.47 \times f_{44}+0.01$, the relationship between $\kappa_{\mathrm{OA}}$ and $\mathrm{O}: \mathrm{C}$ can be expressed as $\kappa_{\mathrm{OA}}=0.3 \times \mathrm{O}: \mathrm{C}-0.02$. The derived empirical relationship between $\kappa_{\mathrm{OA}}$ and $f_{44}$ was compared to results in previous studies (Fig. 7b). As mentioned in Sect. 2.3, the $f_{44}$ from CV-ToF-ACSM measurements is much higher than that previously reported from AMS, but they are well correlated, and the ratio between the $f_{44}$ of CV-ToF-ACSM and previous AMS instruments for ambient aerosol ranges from 1.5 to 2 , with an average of 1.75 . Therefore, to be consistent with the $f_{44}$ in previous studies, the empirical relationship in Fig. $7 \mathrm{~b}$ is changed to $\kappa_{\mathrm{OA}}=1.79 \cdot f_{44}-0.03$. The $\kappa_{\mathrm{OA}}$ values are lower than those from the scheme of Chen et al. (2017) but higher than those in Duplissy et al. (2011) and Mei et al. (2013a). In general, results of most published studies about $\kappa_{\mathrm{OA}}$ demonstrate that hygroscopicity of organic aerosol generally increases as 

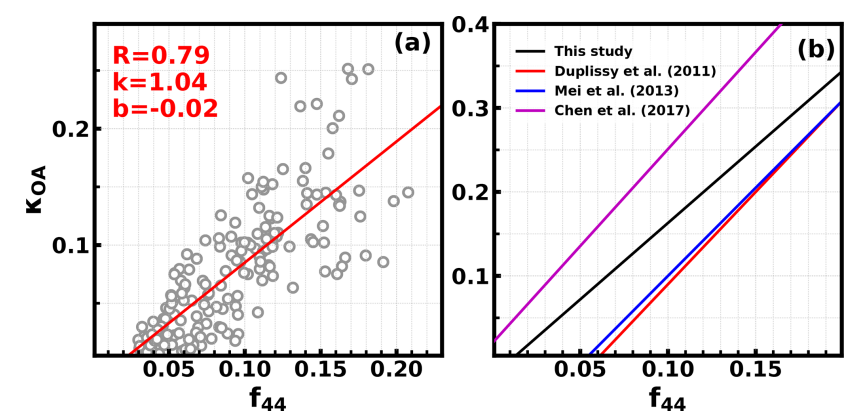

Figure 7. (a) The relationship between derived $\kappa_{\mathrm{OA}}$ and $f_{44}$. (b) Comparison with previous studies.

the oxidation level of organic aerosol increases; however, the empirical mathematical relationship differs much among different studies (Hong et al., 2018). These results highlight that more studies are required to study the influence of the OA oxidation level on $\kappa_{\mathrm{OA}}$ and to derive a more universal parameterization scheme that can be used in chemical transport models.

\subsection{Distinct diurnal variations in $\kappa_{\mathrm{OA}}$ and its relationship with $\mathrm{OOA}$}

The time series of derived $\kappa_{\mathrm{OA}}$ are depicted in Fig. 8a, which showed large fluctuations in a day. The average $\kappa_{\mathrm{OA}}$ (Fig. 8b) displays a distinct diurnal variation, with $\kappa_{\mathrm{OA}}$ reaching its minimum (0.02) in the morning (near 07:30 LT) and increasing quickly to a maximum (0.16) near 14:30 LT. As a consequence, the water uptake abilities of organic aerosol particles changed from nearly hydrophobic to moderately hygroscopic within $7 \mathrm{~h}$ during the day. Previous results from observations in Japan also revealed significant $\kappa_{\mathrm{OA}}$ diurnal variations, though with daily minima in the afternoon hours due to the increase in less oxygenated OA mass fractions (Deng et al., 2018, 2019). Such large variability and significant diurnal variations in $\kappa_{\mathrm{OA}}$ were observed for the first time on the NCP. We found that the diurnal profile of the mass fraction OOA in OA $\left(f_{\mathrm{OOA}}\right)$ was remarkably similar to that of $\kappa_{\mathrm{OA}}$ $(R=0.8$; Fig. $8 \mathrm{a}$ and $\mathrm{c})$, suggesting that OOA is very likely the determining factor of $\kappa_{\mathrm{OA}}$ in winter on the NCP.

The correlation coefficient between the average diurnal profiles of $\kappa_{\mathrm{OA}}$ and $f_{\mathrm{OOA}}$ was 0.95 , which suggests that the variations in $f_{\mathrm{OOA}}$ were driving the significant diurnal variations in $\kappa_{\mathrm{OA}}$. The average diurnal variations in mass concentrations of identified OOA, HOA, COA, CCOA, BBOA, and their mass fractions in total organic mass are shown in Fig. 9a and b, respectively. The mass concentrations of HOA, CCOA, and BBOA decreased rapidly from the morning to 15:00 LT due to the rising boundary layer height and also to the decreased primary source emissions. The mass concentrations of COA increased a little in the morning and then decreased quickly after 09:30 LT. This transitory increase in $\mathrm{COA}$ in the morning might be associated with cooking for
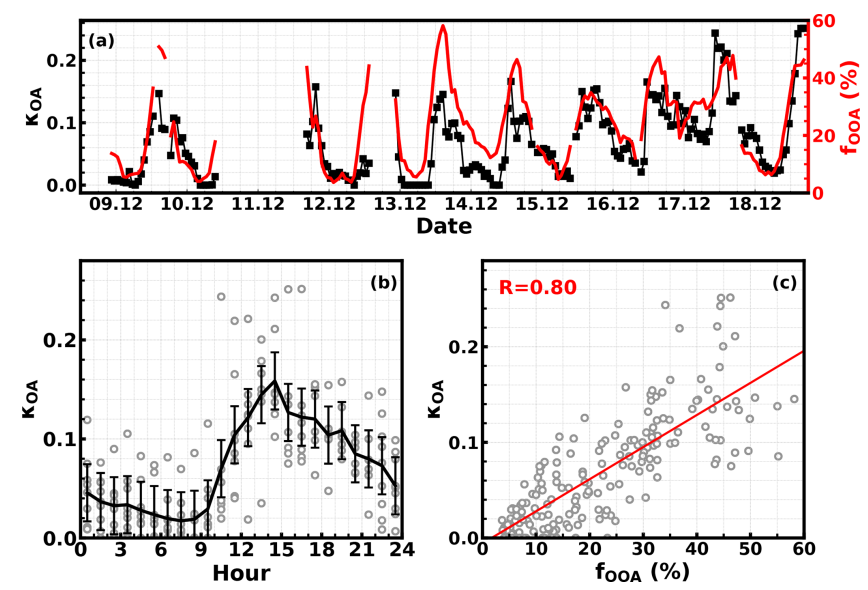

Figure 8. (a) Time series of derived $\kappa_{\mathrm{OA}}$ and OOA mass fraction in $\mathrm{NR}^{\mathrm{PM}} \mathrm{M}_{1}\left(f_{\mathrm{OOA}}\right)$ on the right $y$ axis. (b) Average diurnal profile of $\kappa_{\mathrm{OA}}$. (c) Scatter points of $\kappa_{\mathrm{OA}}$ versus $f_{\mathrm{OOA}}(\%)$, and red line is the fitting line with linear regression.
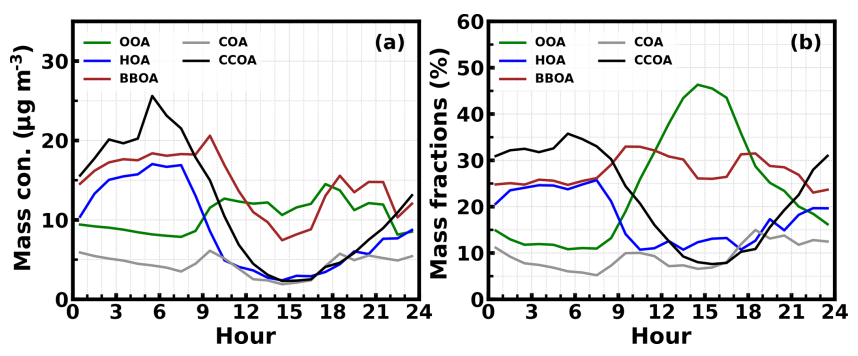

Figure 9. (a) Average diurnal profiles of mass concentrations of OOA, HOA, COA, CCOA, and BBOA. (b) Average diurnal variations in mass fractions of OOA, HOA, COA, CCOA, and BBOA.

breakfast. However, the OOA mass increased rapidly from about 07:30 to 10:30 LT despite the boundary layer development during period of time and then remained almost constant thereafter. The rapid decreases in primary organic aerosol components and the increases in OOA concentration together resulted in a dramatic increase in $f_{\mathrm{OOA}}$, from $\sim 10 \%$ at 09:00 LT to $\sim 45 \%$ at 13:30 LT in the afternoon, which also corresponds to the similar increase in $\kappa_{\mathrm{OA}}$. After 14:30 LT, the OOA mass concentration remained relatively unchanged; however, of the large increases in primary organic aerosol components, it also led to considerable decreases in $f_{\mathrm{OOA}}$ and $\kappa_{\mathrm{OA}}$.

\section{Conclusions}

A field campaign was conducted at a rural site on the North China Plain in winter 2018. The major instruments deployed were a humidified nephelometer system and a CVToF-ACSM for the measurements of the bulk aerosol hygroscopicity of $\mathrm{PM}_{10}$ and $\mathrm{PM}_{1}$ and bulk aerosol chemical compositions of $\mathrm{PM}_{2.5}$ and $\mathrm{PM}_{1}$. The measured $\sigma_{\mathrm{sp}}$ at $525 \mathrm{~nm}$ of 
$\mathrm{PM}_{1}$ and $\mathrm{PM}_{10}$ in the dry state ranged from 11 to $1875 \mathrm{Mm}^{-1}$ and from 18 to $2732 \mathrm{Mm}^{-1}$, with average values of 550 and $814 \mathrm{Mm}^{-1}$, respectively, suggesting a relatively polluted environment during this study. Retrieved $\kappa_{f(\mathrm{RH})}$ of $\mathrm{PM}_{10}$ and $\mathrm{PM}_{1}$ ranged from 0.02 to 0.27 and from 0.03 to 0.26 , with averages of 0.12 and 0.12 , respectively. The difference of $\kappa_{f}(\mathrm{RH})$ between $\mathrm{PM}_{10}$ and $\mathrm{PM}_{1}$ was found to be relatively small (3.5\% on average), which was consistent with the physical and mathematical interpretation of $\kappa_{f}(\mathrm{RH})$.

A method for estimating $\kappa_{\mathrm{OA}}$ (organic aerosol hygroscopicity) based on $f(\mathrm{RH})$ and bulk aerosol chemicalcomposition measurements is developed. The key part of this method is that the size cut of bulk aerosol chemicalcomposition measurements should be $\mathrm{PM}_{1}$ no matter whether the bulk $\kappa_{f(\mathrm{RH})}$ is retrieved from light-scattering enhancement measurements of $\mathrm{PM}_{1}$ or $\mathrm{PM}_{10}$. The derived $\kappa_{\mathrm{OA}}$ ranged from 0.0 to 0.25 , with an average of 0.08 , highlighting that $\kappa_{\mathrm{OA}}$ displayed a large variability on the NCP. Therefore, using a constant $\kappa_{\mathrm{OA}}$ could introduce a considerable uncertainty in evaluating the climatic and environmental effects of organic aerosol. The variation in $\kappa_{\mathrm{OA}}$ was highly and positively correlated with the oxidation degree of OA, and $\kappa_{\mathrm{OA}}$ showed a distinct diurnal variation, with the minimum in the morning (0.02) and maximum in the afternoon (0.16). These results indicated the rapid changes in hygroscopic properties of OA in a day by evolving from nearly hydrophobic to moderately hygroscopic within $7 \mathrm{~h}$. The distinct diurnal variations in $\kappa_{\mathrm{OA}}$ were strongly associated with the changes in $f_{\mathrm{OOA}}$, suggesting that the rapid formation of OOA together with the decreases in primary organic aerosol during daytime together resulted in and the changes in $\kappa_{\mathrm{OA}}$.

The large variability and distinct diurnal variations in $\kappa_{\mathrm{OA}}$ found in this study highlight an urgent need for more studies on the spatial and temporal variations in $\kappa_{\mathrm{OA}}$ in the NCP region and also a better parameterization of $\kappa_{\mathrm{OA}}$ in chemical transport models to evaluate the impacts of OA on radiative forcing and $\mathrm{CCN}$.

Data availability. The data used in this study are listed in the references and a repository at https://pan.baidu.com/s/ 16dOPuTQ568z5JRGF0jGLHQ (last access: 21 January 2020; both python and MATLAB format) and are also available from the corresponding author upon request (kuangye@jnu.edu.cn and sunyele@mail.iap.ac.cn).

Supplement. The supplement related to this article is available online at: https://doi.org/10.5194/acp-20-865-2020-supplement.

Author contributions. YK conceived and organized this paper. YC, HS, NM, YK, and JT planned this campaign. YK, YS, and NM designed the experiments. YK and YH conducted the ACSM and aerosol light-scattering enhancement factor measurements. $\mathrm{YZ}$ and SZ conducted the particle number size distribution measurements.
JS and WY conducted the black carbon measurements. YH performed the ACSM PMF analysis. WX, YH, YS, CZ, PZ, and YC helped the data analysis, and WX helped much with the language editing. YK, YH, and YS prepared the paper, with contributions from all co-authors.

Competing interests. The authors declare that they have no conflict of interest.

Acknowledgements. We thank the technician LinHong Xie for help assembling the inlet system and maintaining the humidified nephelometer system. We also thank the scientists and technicians from the Max Planck Institute for Chemistry, Mainz, for supporting this field campaign.

Financial support. This research has been supported by the National Key Research and Development Program of China (grant no. 2017YFC0210104), the National Natural Science Foundation of China (grant no. 91644218), and the National Research Program for Key Issues in Air Pollution Control (grant no. DQGG0103). This work is supported by the National Natural Science Foundation of China (grant no. 41805109) and the Guangdong Innovative and Entrepreneurial Research Team Program (research team on atmospheric environmental roles and effects of carbonaceous species: 2016ZT06N263).

Review statement. This paper was edited by James Allan and reviewed by two anonymous referees.

\section{References}

Bergin, M. H., Cass, G. R., Xu, J., Fang, C., Zeng, L. M., Yu, T., Salmon, L. G., Kiang, C. S., Tang, X. Y., Zhang, Y. H., and Chameides, W. L.: Aerosol radiative, physical, and chemical properties in Beijing during June 1999, J. Geophys. Res.-Atmos., 106, 17969-17980, https://doi.org/10.1029/2001jd900073, 2001.

Bian, Y. X., Zhao, C. S., Ma, N., Chen, J., and Xu, W. Y.: A study of aerosol liquid water content based on hygroscopicity measurements at high relative humidity in the North China Plain, Atmos. Chem. Phys., 14, 6417-6426, https://doi.org/10.5194/acp14-6417-2014, 2014.

Bougiatioti, A., Bezantakos, S., Stavroulas, I., Kalivitis, N., Kokkalis, P., Biskos, G., Mihalopoulos, N., Papayannis, A., and Nenes, A.: Biomass-burning impact on CCN number, hygroscopicity and cloud formation during summertime in the eastern Mediterranean, Atmos. Chem. Phys., 16, 7389-7409, https://doi.org/10.5194/acp-16-7389-2016, 2016.

Brock, C. A., Wagner, N. L., Anderson, B. E., Attwood, A. R., Beyersdorf, A., Campuzano-Jost, P., Carlton, A. G., Day, D. A., Diskin, G. S., Gordon, T. D., Jimenez, J. L., Lack, D. A., Liao, J., Markovic, M. Z., Middlebrook, A. M., Ng, N. L., Perring, A. E., Richardson, M. S., Schwarz, J. P., Washenfelder, R. A., 
Welti, A., Xu, L., Ziemba, L. D., and Murphy, D. M.: Aerosol optical properties in the southeastern United States in summer - Part 1: Hygroscopic growth, Atmos. Chem. Phys., 16, 49875007, https://doi.org/10.5194/acp-16-4987-2016, 2016.

Cerully, K. M., Bougiatioti, A., Hite Jr., J. R., Guo, H., Xu, L., $\mathrm{Ng}$, N. L., Weber, R., and Nenes, A.: On the link between hygroscopicity, volatility, and oxidation state of ambient and water-soluble aerosols in the southeastern United States, Atmos. Chem. Phys., 15, 8679-8694, https://doi.org/10.5194/acp15-8679-2015, 2015.

Chang, R. Y.-W., Slowik, J. G., Shantz, N. C., Vlasenko, A., Liggio, J., Sjostedt, S. J., Leaitch, W. R., and Abbatt, J. P. D.: The hygroscopicity parameter $(\kappa)$ of ambient organic aerosol at a field site subject to biogenic and anthropogenic influences: relationship to degree of aerosol oxidation, Atmos. Chem. Phys., 10, 5047-5064, https://doi.org/10.5194/acp-10-5047-2010, 2010.

Chen, J., Zhao, C. S., Ma, N., and Yan, P.: Aerosol hygroscopicity parameter derived from the light scattering enhancement factor measurements in the North China Plain, Atmos. Chem. Phys., 14, 8105-8118, https://doi.org/10.5194/acp-14-8105-2014, 2014.

Chen, J., Budisulistiorini, S. H., Itoh, M., Lee, W.-C., Miyakawa, T., Komazaki, Y., Yang, L. D. Q., and Kuwata, M.: Water uptake by fresh Indonesian peat burning particles is limited by watersoluble organic matter, Atmos. Chem. Phys., 17, 11591-11604, https://doi.org/10.5194/acp-17-11591-2017, 2017.

Cheng, Y. F., Wiedensohler, A., Eichler, H., Su, H., Gnauk, T., Brueggemann, E., Herrmann, H., Heintzenberg, J., Slanina, J., Tuch, T., Hu, M., and Zhang, Y. H.: Aerosol optical properties and related chemical apportionment at Xinken in Pearl River Delta of China, Atmos. Environ., 42, 6351-6372, https://doi.org/10.1016/j.atmosenv.2008.02.034, 2008.

Deng, Y., Kagami, S., Ogawa, S., Kawana, K., Nakayama, T., Kubodera, R., Adachi, K., Hussein, T., Miyazaki, Y., and Mochida, M.: Hygroscopicity of Organic Aerosols and Their Contributions to $\mathrm{CCN}$ Concentrations Over a Midlatitude Forest in Japan, J. Geophys. Res.-Atmos., 123, 9703-9723, https://doi.org/10.1029/2017jd027292, 2018.

Deng, Y., Yai, H., Fujinari, H., Kawana, K., Nakayama, T., and Mochida, M.: Diurnal variation and size dependence of the hygroscopicity of organic aerosol at a forest site in Wakayama, Japan: their relationship to CCN concentrations, Atmos. Chem. Phys., 19, 5889-5903, https://doi.org/10.5194/acp19-5889-2019, 2019.

Drinovec, L., Močnik, G., Zotter, P., Prévôt, A. S. H., Ruckstuhl, C., Coz, E., Rupakheti, M., Sciare, J., Müller, T., Wiedensohler, A., and Hansen, A. D. A.: The "dual-spot" Aethalometer: an improved measurement of aerosol black carbon with realtime loading compensation, Atmos. Meas. Tech., 8, 1965-1979, https://doi.org/10.5194/amt-8-1965-2015, 2015.

Duplissy, J., DeCarlo, P. F., Dommen, J., Alfarra, M. R., Metzger, A., Barmpadimos, I., Prevot, A. S. H., Weingartner, E., Tritscher, T., Gysel, M., Aiken, A. C., Jimenez, J. L., Canagaratna, M. R., Worsnop, D. R., Collins, D. R., Tomlinson, J., and Baltensperger, U.: Relating hygroscopicity and composition of organic aerosol particulate matter, Atmos. Chem. Phys., 11, 11551165, https://doi.org/10.5194/acp-11-1155-2011, 2011.

Fröhlich, R., Cubison, M. J., Slowik, J. G., Bukowiecki, N., Prévôt, A. S. H., Baltensperger, U., Schneider, J., Kimmel, J. R., Gonin, M., Rohner, U., Worsnop, D. R., and Jayne, J. T.: The
ToF-ACSM: a portable aerosol chemical speciation monitor with TOFMS detection, Atmos. Meas. Tech., 6, 3225-3241, https://doi.org/10.5194/amt-6-3225-2013, 2013.

Frosch, M., Bilde, M., DeCarlo, P. F., Jurányi, Z., Tritscher, T., Dommen, J., Donahue, N. M., Gysel, M., Weingartner, E., and Baltensperger, U.: Relating cloud condensation nuclei activity and oxidation level of á-pinene secondary organic aerosols, J. Geophys. Res.-Atmos., 116, D22212, https://doi.org/10.1029/2011jd016401, 2011.

Gysel, M., Crosier, J., Topping, D. O., Whitehead, J. D., Bower, K. N., Cubison, M. J., Williams, P. I., Flynn, M. J., McFiggans, G. B., and Coe, H.: Closure study between chemical composition and hygroscopic growth of aerosol particles during TORCH2, Atmos. Chem. Phys., 7, 6131-6144, https://doi.org/10.5194/acp7-6131-2007, 2007.

Hong, J., Kim, J., Nieminen, T., Duplissy, J., Ehn, M., Äijälä, M., Hao, L. Q., Nie, W., Sarnela, N., Prisle, N. L., Kulmala, M., Virtanen, A., Petäjä, T., and Kerminen, V.-M.: Relating the hygroscopic properties of submicron aerosol to both gas- and particle-phase chemical composition in a boreal forest environment, Atmos. Chem. Phys., 15, 11999-12009, https://doi.org/10.5194/acp-15-11999-2015, 2015.

Hong, J., Xu, H., Tan, H., Yin, C., Hao, L., Li, F., Cai, M., Deng, X., Wang, N., Su, H., Cheng, Y., Wang, L., Petäjä, T., and Kerminen, V.-M.: Mixing state and particle hygroscopicity of organic-dominated aerosols over the Pearl River Delta region in China, Atmos. Chem. Phys., 18, 14079-14094, https://doi.org/10.5194/acp-18-14079-2018, 2018.

Hu, W., Campuzano-Jost, P., Day, D. A., Croteau, P., Canagaratna, M. R., Jayne, J. T., Worsnop, D. R., and Jimenez, J. L.: Evaluation of the new capture vapourizer for aerosol mass spectrometers (AMS) through laboratory studies of inorganic species, Atmos. Meas. Tech., 10, 2897-2921, https://doi.org/10.5194/amt10-2897-2017, 2017.

Hu, W., Day, D. A., Campuzano-Jost, P., Nault, B. A., Park, T., Lee, T., Croteau, P., Canagaratna, M. R., Jayne, J. T., Worsnop, D. R., and Jimenez, J. L.: Evaluation of the new capture vaporizer for aerosol mass spectrometers: Characterization of organic aerosol mass spectra, Aerosol Sci. Technol., 52, 725-739, https://doi.org/10.1080/02786826.2018.1454584, 2018a.

Hu, W., Day, D. A., Campuzano-Jost, P., Nault, B. A., Park, T., Lee, T., Croteau, P., Canagaratna, M. R., Jayne, J. T., Worsnop, D. R., and Jimenez, J. L.: Evaluation of the New Capture Vaporizer for Aerosol Mass Spectrometers (AMS): Elemental Composition and Source Apportionment of Organic Aerosols (OA), ACS Earth and Space Chemistry, 2, 410-421, https://doi.org/10.1021/acsearthspacechem.8b00002, $2018 \mathrm{~b}$.

Jimenez, J. L., Canagaratna, M. R., Donahue, N. M., Prevot, A. S. H., Zhang, Q., Kroll, J. H., DeCarlo, P. F., Allan, J. D., Coe, H., Ng, N. L., Aiken, A. C., Docherty, K. S., Ulbrich, I. M., Grieshop, A. P., Robinson, A. L., Duplissy, J., Smith, J. D., Wilson, K. R., Lanz, V. A., Hueglin, C., Sun, Y. L., Tian, J., Laaksonen, A., Raatikainen, T., Rautiainen, J., Vaattovaara, P., Ehn, M., Kulmala, M., Tomlinson, J. M., Collins, D. R., Cubison, M. J., Dunlea, J., Huffman, J. A., Onasch, T. B., Alfarra, M. R., Williams, P. I., Bower, K., Kondo, Y., Schneider, J., Drewnick, F., Borrmann, S., Weimer, S., Demerjian, K., Salcedo, D., Cottrell, L., Griffin, R., Takami, A., Miyoshi, T., Hatakeyama, S., Shimono, A., Sun, J. Y., Zhang, Y. M., Dzepina, K., Kimmel, 
J. R., Sueper, D., Jayne, J. T., Herndon, S. C., Trimborn, A. M., Williams, L. R., Wood, E. C., Middlebrook, A. M., Kolb, C. E., Baltensperger, U., and Worsnop, D. R.: Evolution of Organic Aerosols in the Atmosphere, Science, 326, 1525-1529, https://doi.org/10.1126/science.1180353, 2009.

Kawana, K., Nakayama, T., and Mochida, M.: Hygroscopicity and $\mathrm{CCN}$ activity of atmospheric aerosol particles and their relation to organics: Characteristics of urban aerosols in Nagoya, Japan, J. Geophys. Res.-Atmos., 121, 4100-4121, https://doi.org/10.1002/2015JD023213, 2016.

Koehler, K. A., Kreidenweis, S. M., DeMott, P. J., Petters, M. D., Prenni, A. J., and Carrico, C. M.: Hygroscopicity and cloud droplet activation of mineral dust aerosol, Geophys. Res. Lett., 36, L08805, https://doi.org/10.1029/2009GL037348, 2009.

Kuang, Y., Zhao, C., Tao, J., Bian, Y., Ma, N., and Zhao, G.: A novel method for deriving the aerosol hygroscopicity parameter based only on measurements from a humidified nephelometer system, Atmos. Chem. Phys., 17, 6651-6662, https://doi.org/10.5194/acp-17-6651-2017, 2017.

Kuang, Y., Zhao, C. S., Zhao, G., Tao, J. C., Xu, W., Ma, N., and Bian, Y. X.: A novel method for calculating ambient aerosol liquid water content based on measurements of a humidified nephelometer system, Atmos. Meas. Tech., 11, 2967-2982, https://doi.org/10.5194/amt-11-2967-2018, 2018.

Lambe, A. T., Onasch, T. B., Massoli, P., Croasdale, D. R., Wright, J. P., Ahern, A. T., Williams, L. R., Worsnop, D. R., Brune, W. H., and Davidovits, P.: Laboratory studies of the chemical composition and cloud condensation nuclei $(\mathrm{CCN})$ activity of secondary organic aerosol (SOA) and oxidized primary organic aerosol (OPOA), Atmos. Chem. Phys., 11, 8913-8928, https://doi.org/10.5194/acp-11-8913-2011, 2011.

Li, X., Song, S., Zhou, W., Hao, J., Worsnop, D. R., and Jiang, J.: Interactions between aerosol organic components and liquid water content during haze episodes in Beijing, Atmos. Chem. Phys., 19, 12163-12174, https://doi.org/10.5194/acp-19-121632019, 2019.

Liu, H. J., Zhao, C. S., Nekat, B., Ma, N., Wiedensohler, A., van Pinxteren, D., Spindler, G., Müller, K., and Herrmann, H.: Aerosol hygroscopicity derived from size-segregated chemical composition and its parameterization in the North China Plain, Atmos. Chem. Phys., 14, 2525-2539, https://doi.org/10.5194/acp-14-2525-2014, 2014.

Liu, X. and Wang, J.: How important is organic aerosol hygroscopicity to aerosol indirect forcing?, Environ. Res. Lett., 5, 044010, https://doi.org/10.1088/1748-9326/5/4/044010, 2010.

Ma, N., Zhao, C. S., Nowak, A., Müller, T., Pfeifer, S., Cheng, Y. F., Deng, Z. Z., Liu, P. F., Xu, W. Y., Ran, L., Yan, P., Göbel, T., Hallbauer, E., Mildenberger, K., Henning, S., Yu, J., Chen, L. L., Zhou, X. J., Stratmann, F., and Wiedensohler, A.: Aerosol optical properties in the North China Plain during HaChi campaign: an in-situ optical closure study, Atmos. Chem. Phys., 11, 5959-5973, https://doi.org/10.5194/acp-11-5959-2011, 2011.

Massoli, P., Lambe, A. T., Ahern, A. T., Williams, L. R., Ehn, M., Mikkilä, J., Canagaratna, M. R., Brune, W. H., Onasch, T. B., Jayne, J. T., Petäjä, T., Kulmala, M., Laaksonen, A., Kolb, C. E., Davidovits, P., and Worsnop, D. R.: Relationship between aerosol oxidation level and hygroscopic properties of laboratory generated secondary organic aerosol (SOA) particles, Geophys.
Res. Lett., 37, L24801, https://doi.org/10.1029/2010g1045258, 2010.

Mei, F., Hayes, P. L., Ortega, A., Taylor, J. W., Allan, J. D., Gilman, J., Kuster, W., de Gouw, J., Jimenez, J. L., and Wang, J.: Droplet activation properties of organic aerosols observed at an urban site during CalNex-LA, J. Geophys. Res.-Atmos., 118, 2903-2917, https://doi.org/10.1002/jgrd.50285, 2013a.

Mei, F., Setyan, A., Zhang, Q., and Wang, J.: CCN activity of organic aerosols observed downwind of urban emissions during CARES, Atmos. Chem. Phys., 13, 12155-12169, https://doi.org/10.5194/acp-13-12155-2013, 2013b.

Paatero, P. and Tapper, U.: Positive matrix factorization: A non-negative factor model with optimal utilization of error estimates of data values, Environmetrics, 5, 111-126, https://doi.org/10.1002/env.3170050203, 1994.

Petters, M. D. and Kreidenweis, S. M.: A single parameter representation of hygroscopic growth and cloud condensation nucleus activity, Atmos. Chem. Phys., 7, 1961-1971, https://doi.org/10.5194/acp-7-1961-2007, 2007.

Quinn, P. K., Coffman, D. J., Bates, T. S., Miller, T. L., Johnson, J. E., Welton, E. J., Neusüss, C., Miller, M., and Sheridan, P. J.: Aerosol optical properties during INDOEX 1999: Means, variability, and controlling factors, J. Geophys. Res.-Atmos., 107, 19-25, https://doi.org/10.1029/2000jd000037, 2002.

Rastak, N., Pajunoja, A., Acosta Navarro, J. C., Ma, J., Song, M., Partridge, D. G., Kirkevåg, A., Leong, Y., Hu, W. W., Taylor, N. F., Lambe, A., Cerully, K., Bougiatioti, A., Liu, P., Krejci, R., Petäjä, T., Percival, C., Davidovits, P., Worsnop, D. R., Ekman, A. M. L., Nenes, A., Martin, S., Jimenez, J. L., Collins, D. R., Topping, D. O., Bertram, A. K., Zuend, A., Virtanen, A., and Riipinen, I.: Microphysical explanation of the RH-dependent water affinity of biogenic organic aerosol and its importance for climate, Geophys. Res. Lett., 44, 5167-5177, https://doi.org/10.1002/2017gl073056, 2017.

Rose, D., Nowak, A., Achtert, P., Wiedensohler, A., Hu, M., Shao, M., Zhang, Y., Andreae, M. O., and Pöschl, U.: Cloud condensation nuclei in polluted air and biomass burning smoke near the mega-city Guangzhou, China - Part 1: Size-resolved measurements and implications for the modeling of aerosol particle hygroscopicity and CCN activity, Atmos. Chem. Phys., 10, 33653383, https://doi.org/10.5194/acp-10-3365-2010, 2010.

Shao, L., Li, W., Yang, S., Shi, Z., and Lü, S.: Mineralogical characteristics of airborne particles collected in Beijing during a severe Asian dust storm period in spring 2002, Sci. China Ser. D, 50, 953-959, 2007.

Sherman, J. P., Sheridan, P. J., Ogren, J. A., Andrews, E., Hageman, D., Schmeisser, L., Jefferson, A., and Sharma, S.: A multi-year study of lower tropospheric aerosol variability and systematic relationships from four North American regions, Atmos. Chem. Phys., 15, 12487-12517, https://doi.org/10.5194/acp-15-124872015, 2015.

Thalman, R., de Sá, S. S., Palm, B. B., Barbosa, H. M. J., Pöhlker, M. L., Alexander, M. L., Brito, J., Carbone, S., Castillo, P., Day, D. A., Kuang, C., Manzi, A., Ng, N. L., Sedlacek III, A. J., Souza, R., Springston, S., Watson, T., Pöhlker, C., Pöschl, U., Andreae, M. O., Artaxo, P., Jimenez, J. L., Martin, S. T., and Wang, J.: CCN activity and organic hygroscopicity of aerosols downwind of an urban region in central Amazonia: seasonal and diel variations and impact of anthropogenic emissions, Atmos. 
Chem. Phys., 17, 11779-11801, https://doi.org/10.5194/acp-1711779-2017, 2017.

Titos, G., Cazorla, A., Zieger, P., Andrews, E., Lyamani, H., Granados-Muñoz, M. J., Olmo, F. J., and AladosArboledas, L.: Effect of hygroscopic growth on the aerosol light-scattering coefficient: A review of measurements, techniques and error sources, Atmos. Environ., 141, 494-507, https://doi.org/10.1016/j.atmosenv.2016.07.021, 2016.

Ulbrich, I. M., Canagaratna, M. R., Zhang, Q., Worsnop, D. R., and Jimenez, J. L.: Interpretation of organic components from Positive Matrix Factorization of aerosol mass spectrometric data, Atmos. Chem. Phys., 9, 2891-2918, https://doi.org/10.5194/acp-92891-2009, 2009.

Wiedensohler, A., Birmili, W., Nowak, A., Sonntag, A., Weinhold, K., Merkel, M., Wehner, B., Tuch, T., Pfeifer, S., Fiebig, M., Fjäraa, A. M., Asmi, E., Sellegri, K., Depuy, R., Venzac, H., Villani, P., Laj, P., Aalto, P., Ogren, J. A., Swietlicki, E., Williams, P., Roldin, P., Quincey, P., Hüglin, C., Fierz-Schmidhauser, R., Gysel, M., Weingartner, E., Riccobono, F., Santos, S., Grüning, C., Faloon, K., Beddows, D., Harrison, R., Monahan, C., Jennings, S. G., O’Dowd, C. D., Marinoni, A., Horn, H.-G., Keck, L., Jiang, J., Scheckman, J., McMurry, P. H., Deng, Z., Zhao, C. S., Moerman, M., Henzing, B., de Leeuw, G., Löschau, G., and Bastian, S.: Mobility particle size spectrometers: harmonization of technical standards and data structure to facilitate high quality long-term observations of atmospheric particle number size distributions, Atmos. Meas. Tech., 5, 657-685, https://doi.org/10.5194/amt-5-657-2012, 2012.

Williams, B. J., Goldstein, A. H., Kreisberg, N. M., Hering, S. V., Worsnop, D. R., Ulbrich, I. M., Docherty, K. S., and Jimenez, J. L.: Major components of atmospheric organic aerosol in southern California as determined by hourly measurements of source marker compounds, Atmos. Chem. Phys., 10, 11577-11603, https://doi.org/10.5194/acp-10-11577-2010, 2010.
Wu, Z. J., Poulain, L., Henning, S., Dieckmann, K., Birmili, W., Merkel, M., van Pinxteren, D., Spindler, G., Müller, K., Stratmann, F., Herrmann, H., and Wiedensohler, A.: Relating particle hygroscopicity and $\mathrm{CCN}$ activity to chemical composition during the HCCT-2010 field campaign, Atmos. Chem. Phys., 13, 79837996, https://doi.org/10.5194/acp-13-7983-2013, 2013.

Wu, Z. J., Zheng, J., Shang, D. J., Du, Z. F., Wu, Y. S., Zeng, L. M., Wiedensohler, A., and Hu, M.: Particle hygroscopicity and its link to chemical composition in the urban atmosphere of Beijing, China, during summertime, Atmos. Chem. Phys., 16, 1123 1138, https://doi.org/10.5194/acp-16-1123-2016, 2016.

$\mathrm{Xu}$, W., Croteau, P., Williams, L., Canagaratna, M., Onasch, T., Cross, E., Zhang, X., Robinson, W., Worsnop, D., and Jayne, J.: Laboratory characterization of an aerosol chemical speciation monitor with $\mathrm{PM}_{2.5}$ measurement capability, Aerosol Sci. Tech. 51, 69-83, https://doi.org/10.1080/02786826.2016.1241859, 2017.

Zhang, F., Li, Y., Li, Z., Sun, L., Li, R., Zhao, C., Wang, P., Sun, Y., Liu, X., Li, J., Li, P., Ren, G., and Fan, T.: Aerosol hygroscopicity and cloud condensation nuclei activity during the AC3Exp campaign: implications for cloud condensation nuclei parameterization, Atmos. Chem. Phys., 14, 13423-13437, https://doi.org/10.5194/acp-14-13423-2014, 2014.

Zhang, Q., Jimenez, J. L., Canagaratna, M. R., Ulbrich, I. M., Ng, N. L., Worsnop, D. R., and Sun, Y.: Understanding atmospheric organic aerosols via factor analysis of aerosol mass spectrometry: a review, Anal. Bioanal. Chem., 401, 3045-3067, https://doi.org/10.1007/s00216-011-5355-y, 2011. 